\title{
SERVICIOS Y CIUDADES EN \\ ANDALUCÍA. NOTAS \\ METODOLÓGICAS
}

G. CANO y Grupo de Investigación "Estudios Geográficos Andaluces»

\section{INTRODUCCIÓN}

Avanzando en la línea investigadora sobre comarcalización, realizamos una encuesta para detectar áreas de influencia en ciertos ámbitos (CANO, 1995), generalizada después al conjunto de pueblos y ciudades andaluces. Preguntábamos dónde se desplazaba la población, en su caso, a fin de adquirir determinados bienes y servicios en una relación de 55 (enseñanza, sanidad, administración, comercio, transportes, ocio y cultura y otros), según puede verse en el cuadro 1.

El cuestionario se envió a 760 municipios (todos salvo las capitales de provincia y urbes populosas, como Jerez o Algeciras, que se suponen autosuficientes), multiplicando por varias unidades para recoger la información de Ayuntamientos, centros de enseñanza media y básica, Juez de paz y agentes locales, entre otros. En una primera fase, finales de 1998, quedaron pueblos sin responder, por lo que se repitió la demanda y, a final de año, sólo restaba un $5 \%$ aproximadamente, cuya información se obtuvo directamente o por teléfono, disponiéndose así de unas dos mil contestaciones.

Fueron numerosas las reunioues del Grupo de Investigación para organizar la informatización de todo el material y homogeneizar criterios sobre algunas cuestiones. Una fue el peso relativo de flujos multidireccionales para un mismo servicio, motivados por desplazamientos desde lugares periféricos más o menos equidistantes de varios polos aprovisionadores ${ }^{1}$.

1. Tras varias aproximaciones, establecimos el siguiente criterio en porcentajes de cada destino: $\mathrm{N}^{\circ}$ de destinos \% contabilizados a cada uno

$\begin{array}{lllll}1 & 100 & & & \\ 2 & 55 & 45 & & \\ 3 & 50 & 30 & 20 & \\ 4 & 40 & 35 & 15 & 10\end{array}$




\section{CUADRO 1}

ENCUESTA SOBRE DESPLAZAMIENTOS

Pueblo o ciudad donde se adquieren:

ARTÍCULOS

- Comestibles especializados

- Confección

- Zapatería

- Electrodomésticos

- Muebles

- Relojería, joyería

- Televisión, vídeos

- Droguería

- Ferretería

- Fotografía

- Deportes

- Material de construcción

- Ordenadores, informática

- Librería

- Loterías, quinielas, etc.

- Automóviles

- Bicicletas y motos

- Butano

- Moda y artesanía

- Optica

- Estanco

\section{GESTIONES}

- Administración Autonómica

- Administración del Estado

- Bancos y Cajas de Ahorros

- Agencias de Seguros

- Correos

\section{REPARACIONES Y SERVICIOS}

- Autoescuelas

- Taxis

- Fontanería

- Carpintería

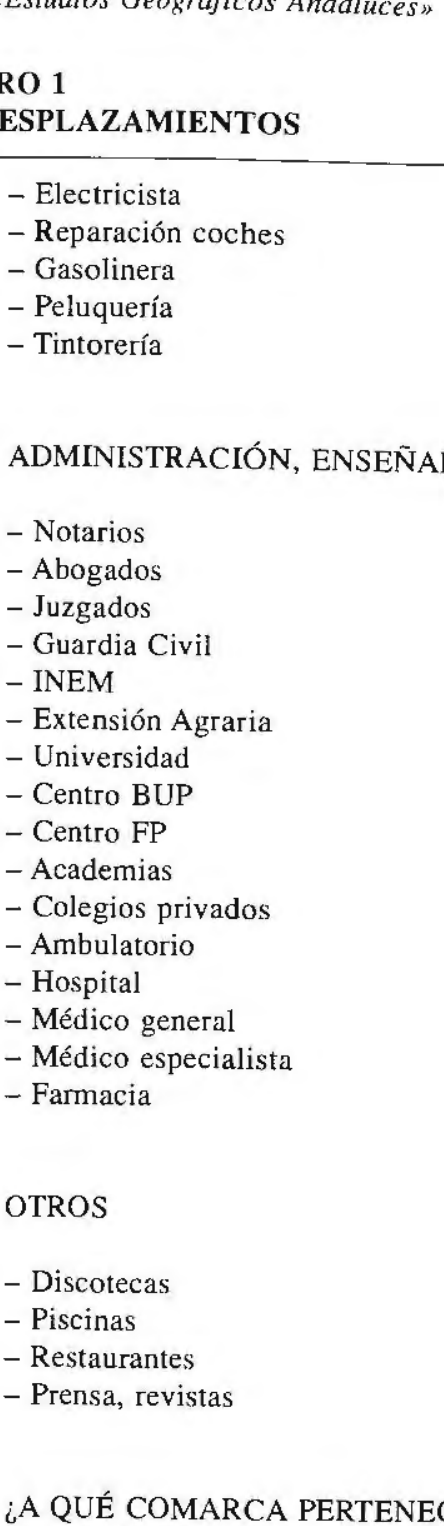

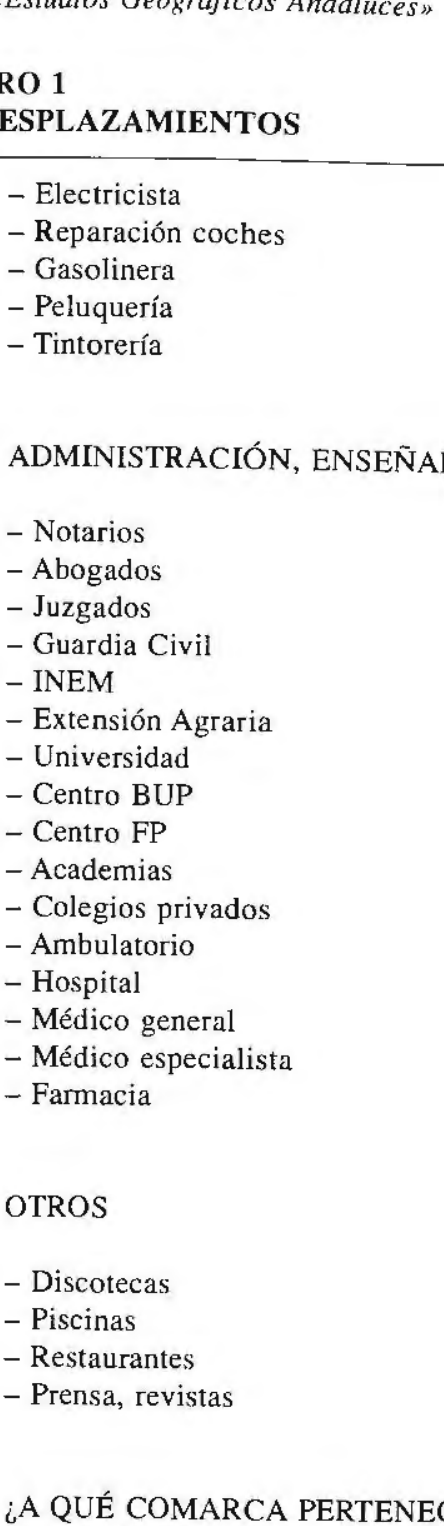

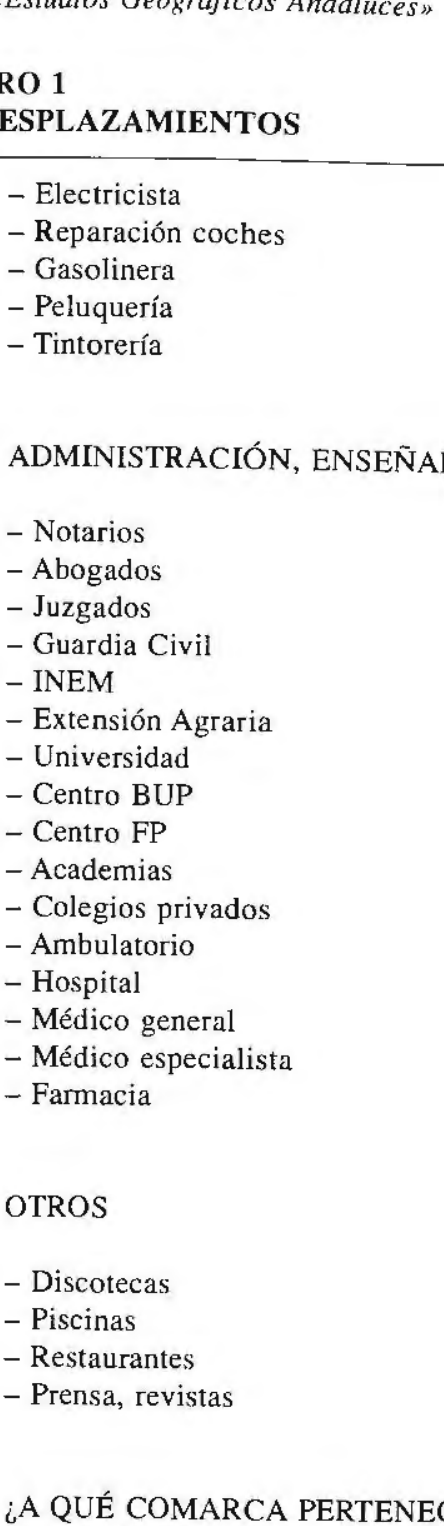

RO 1
- Electricista
- Reparación coches
- Gasolinera
- Peluquería
- Tintorería
ADMINISTRACIÓN, ENSEÑANZTIEN
- Notarios
- Abogados
- Juzgados
- Guardia Civil
- INEM
- Extensión Agraria
- Universidad
- Centro BUP
- Centro FP
- Academias
- Colegios privados
- Ambulatorio
- Hospital
- Médico general
- Médico especialista
- Farmacia
OTROS
- Discotecas
- Piscinas
- Restaurantes
- Prensa, revistas
¿A QUÉ COMARCA PERTENECE

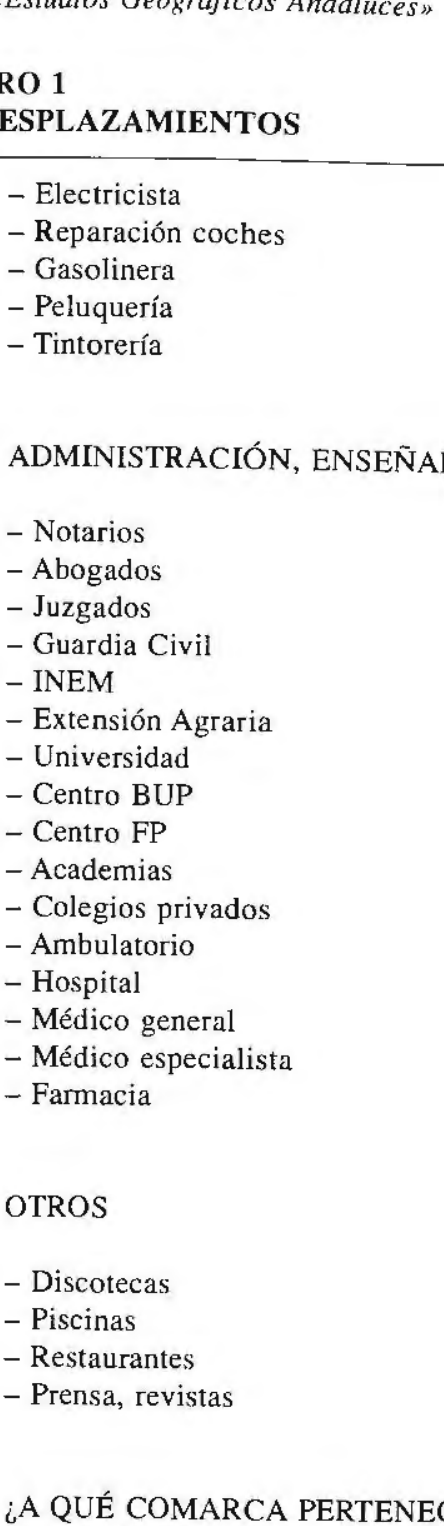

ESPLAZAMIENTOS
- Electricista
- Reparación coches
- Gasolinera
- Peluquería
- Tintorería
ADMINISTRACIÓN, ENSENAANZA, ETC.
- Notarios
- Abogados
- Juzgados
- Guardia Civil
- INEM
- Extensión Agraria
- Universidad
- Centro BUP
- Centro FP
- Academias
- Colegios privados
- Ambulatorio
- Hospital
- Médico general
- Médico especialista
- Farmacia
OTROS
- Discotecas
- Piscinas
- Restaurantes
- Prensa, revistas
¿A QUÉ COMARCA PERTENECE
E

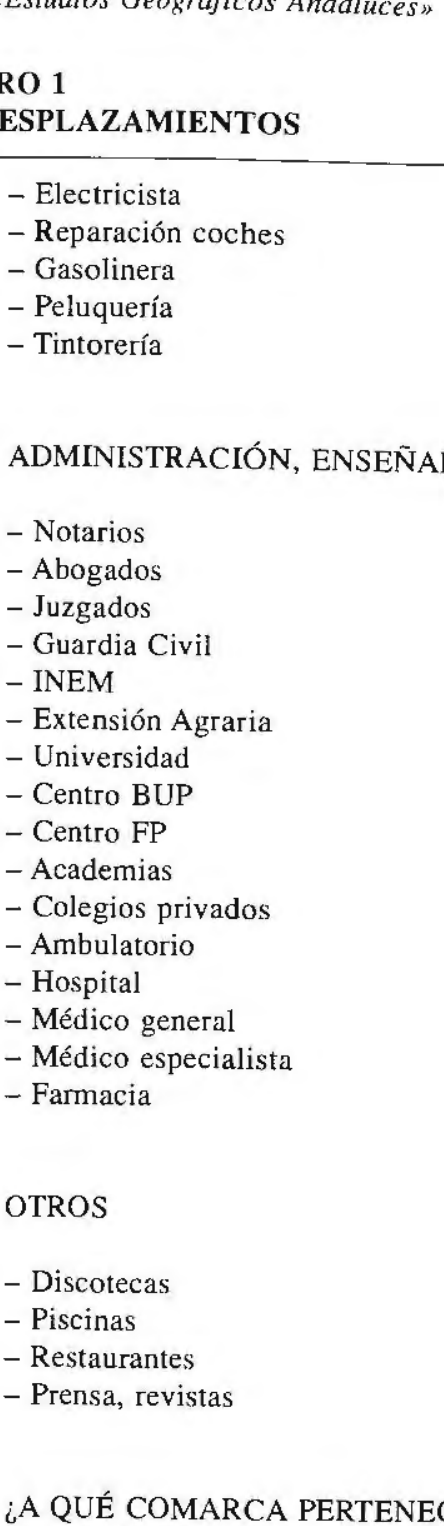

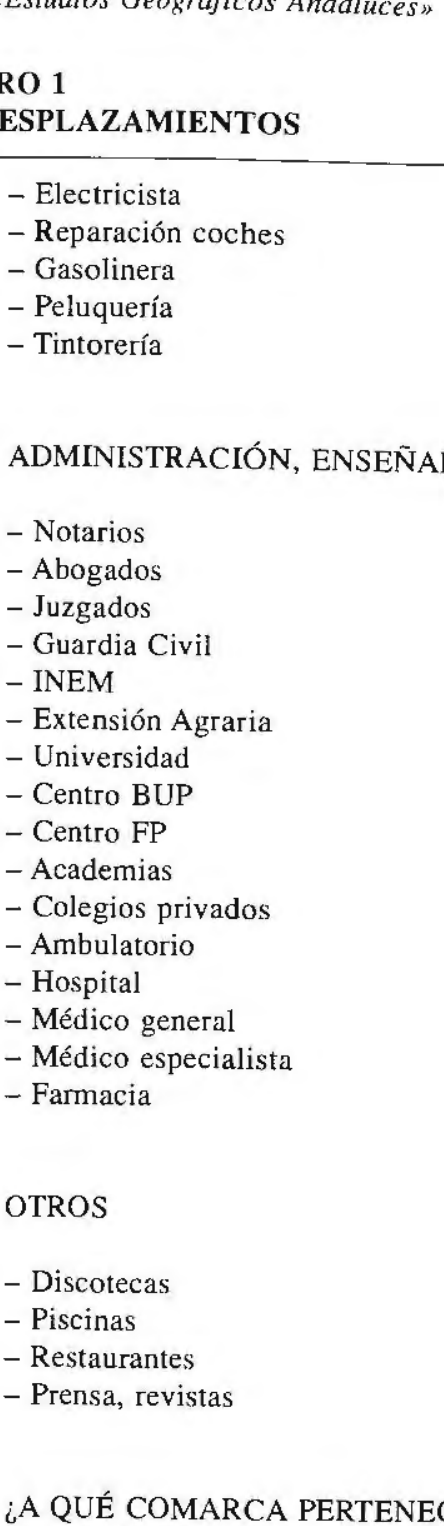

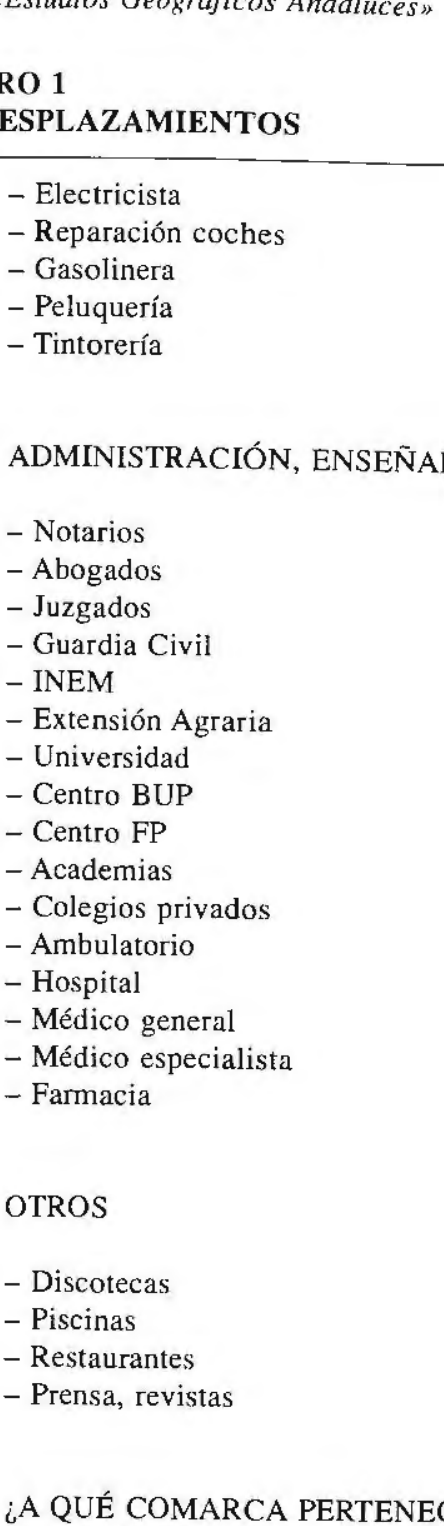

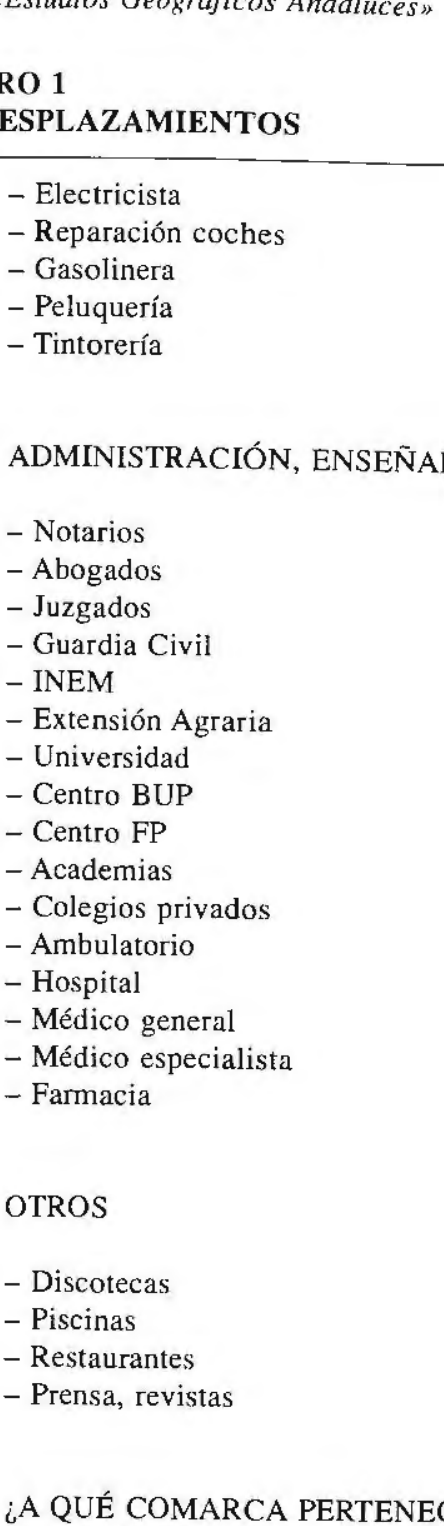

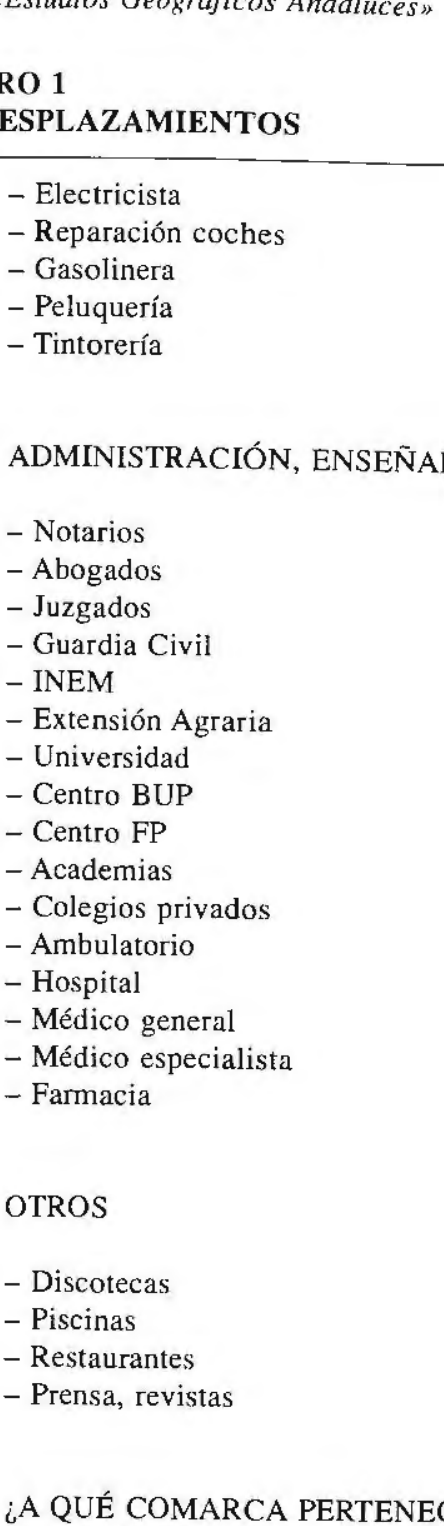

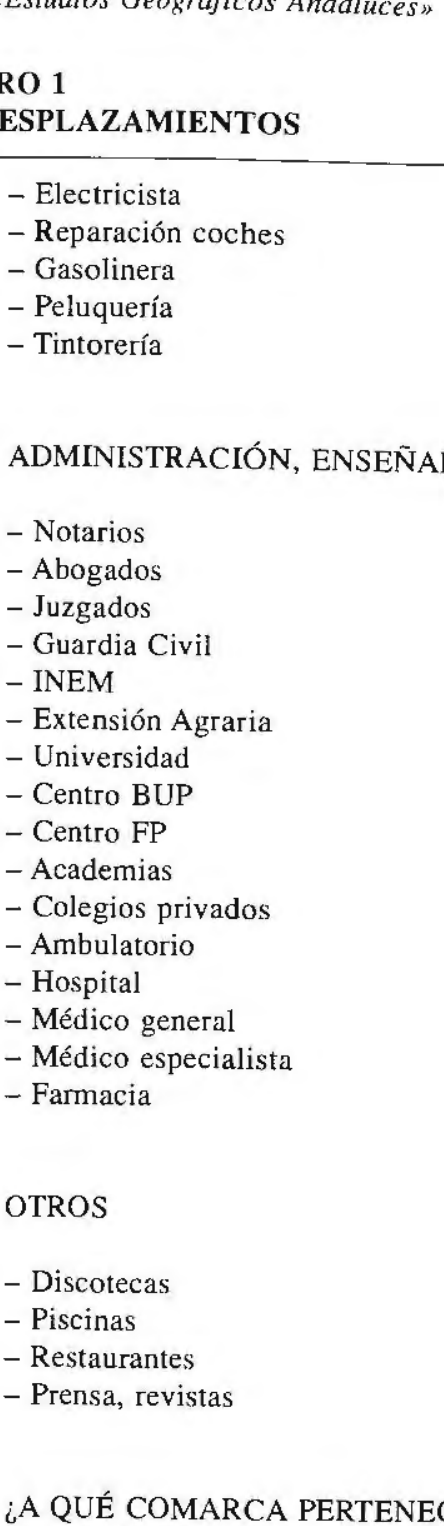

RO 1
- Electricista
- Reparación coches
- Gasolinera
- Peluquería
- Tintorería
ADMINISTRACIÓN, ENSEÑANZTIEN
- Notarios
- Abogados
- Juzgados
- Guardia Civil
- INEM
- Extensión Agraria
- Universidad
- Centro BUP
- Centro FP
- Academias
- Colegios privados
- Ambulatorio
- Hospital
- Médico general
- Médico especialista
- Farmacia
OTROS
- Discotecas
- Piscinas
- Restaurantes
- Prensa, revistas
¿A QUÉ COMARCA PERTENECE

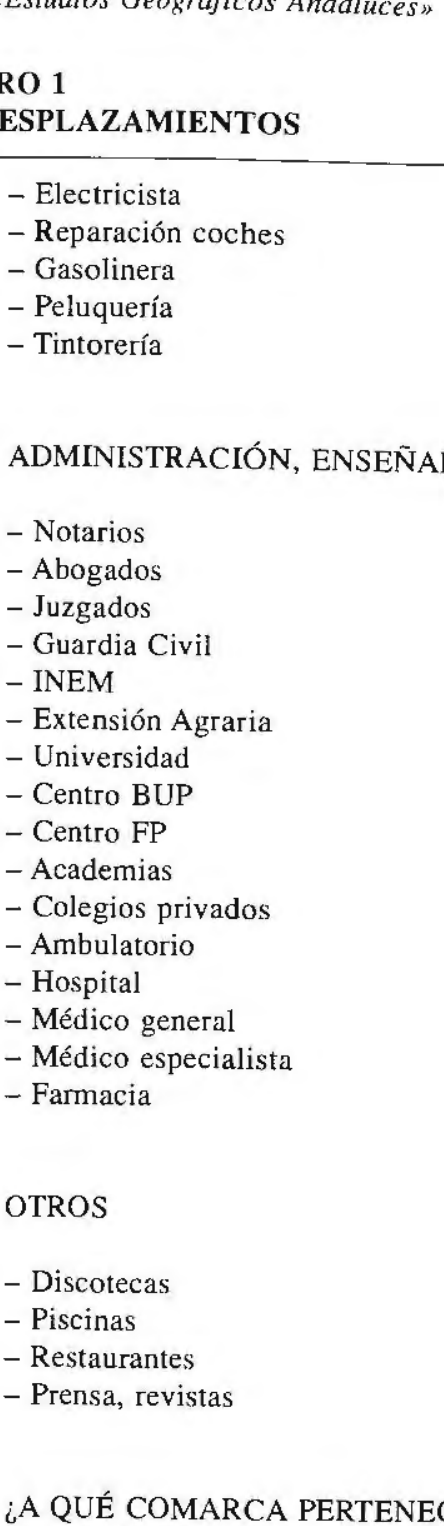

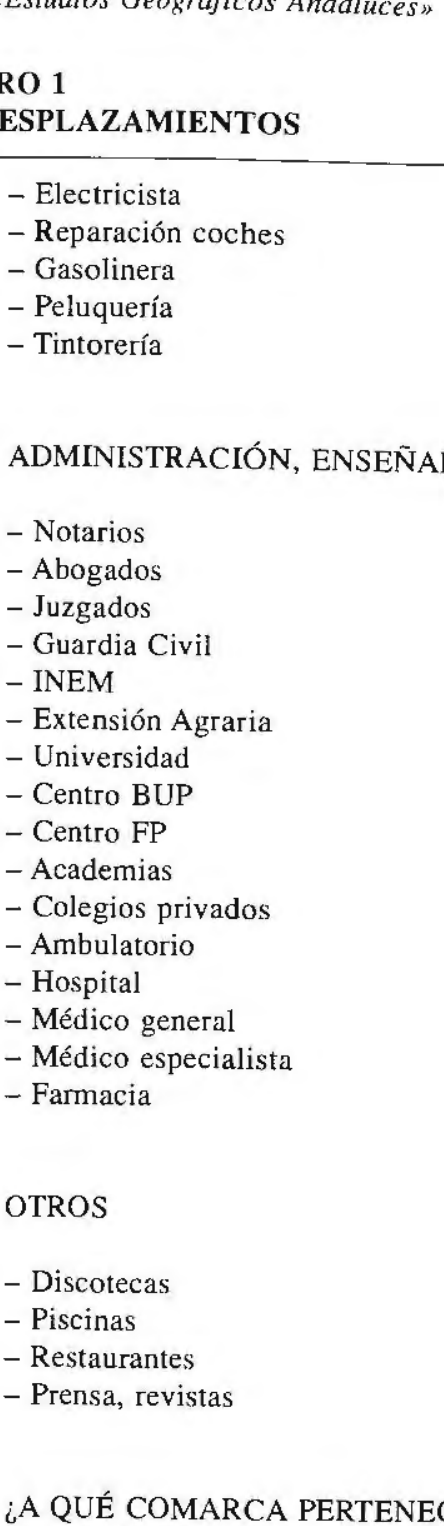

RO 1
- Electricista
- Reparación coches
- Gasolinera
- Peluquería
- Tintorería
ADMINISTRACIÓN, ENSEÑANZTIEN
- Notarios
- Abogados
- Juzgados
- Guardia Civil
- INEM
- Extensión Agraria
- Universidad
- Centro BUP
- Centro FP
- Academias
- Colegios privados
- Ambulatorio
- Hospital
- Médico general
- Médico especialista
- Farmacia
OTROS
- Discotecas
- Piscinas
- Restaurantes
- Prensa, revistas
¿A QUÉ COMARCA PERTENECE

RO 1
- Electricista
- Reparación coches
- Gasolinera
- Peluquería
- Tintorería
ADMINISTRACIÓN, ENSEÑANZTIEN
- Notarios
- Abogados
- Juzgados
- Guardia Civil
- INEM
- Extensión Agraria
- Universidad
- Centro BUP
- Centro FP
- Academias
- Colegios privados
- Ambulatorio
- Hospital
- Médico general
- Médico especialista
- Farmacia
OTROS
- Discotecas
- Piscinas
- Restaurantes
- Prensa, revistas
¿A QUÉ COMARCA PERTENECE

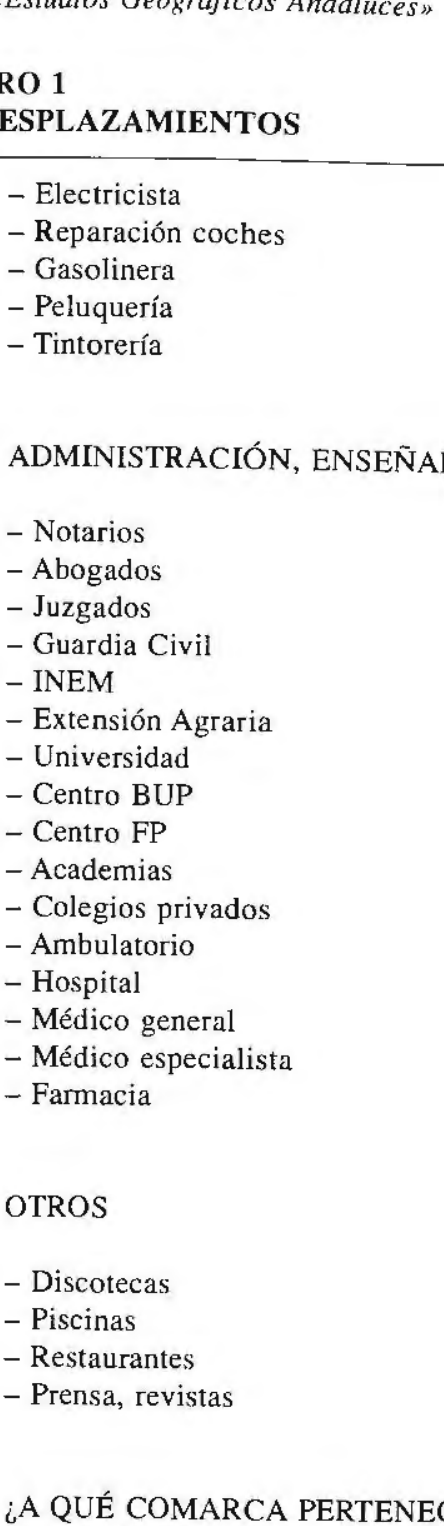

RO 1
- Electricista
- Reparación coches
- Gasolinera
- Peluquería
- Tintorería
ADMINISTRACIÓN, ENSEÑANZTIEN
- Notarios
- Abogados
- Juzgados
- Guardia Civil
- INEM
- Extensión Agraria
- Universidad
- Centro BUP
- Centro FP
- Academias
- Colegios privados
- Ambulatorio
- Hospital
- Médico general
- Médico especialista
- Farmacia
OTROS
- Discotecas
- Piscinas
- Restaurantes
- Prensa, revistas
¿A QUÉ COMARCA PERTENECE

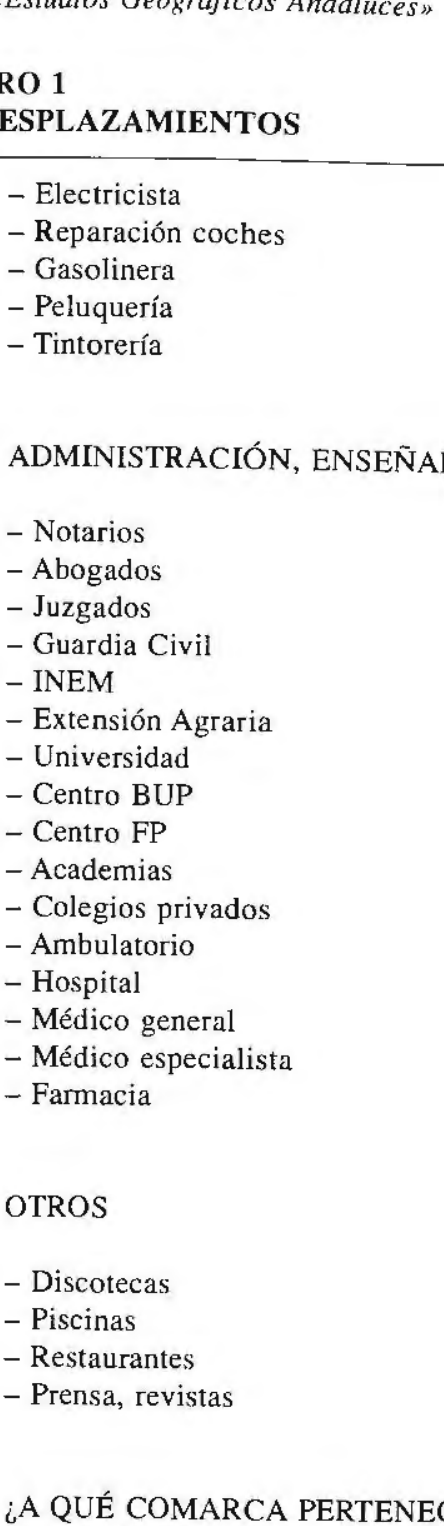

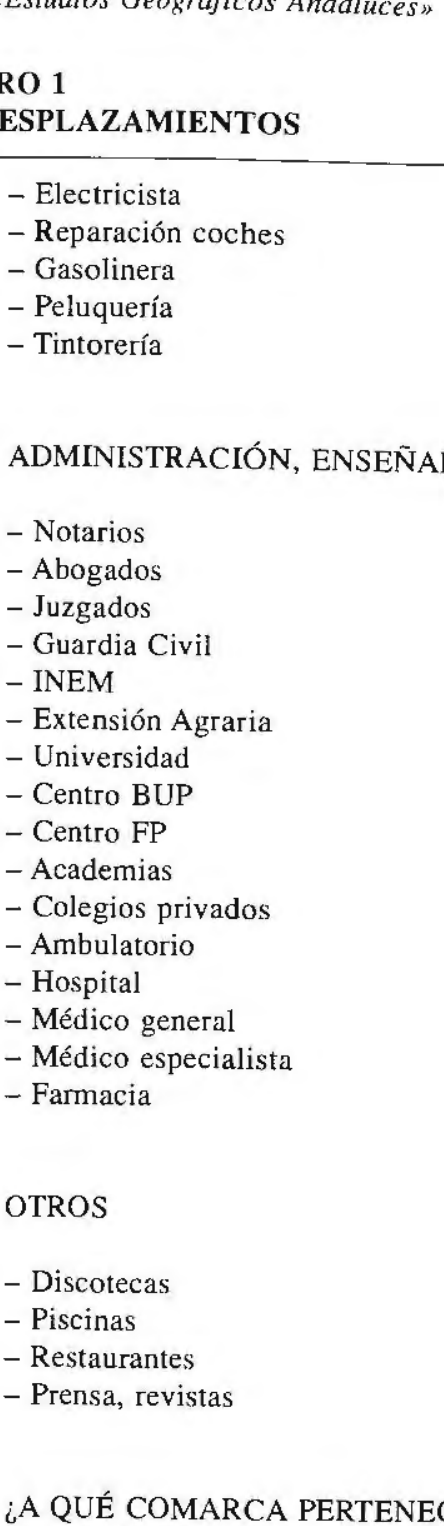

RO 1
- Electricista
- Reparación coches
- Gasolinera
- Peluquería
- Tintorería
ADMINISTRACIÓN, ENSEÑANZTIEN
- Notarios
- Abogados
- Juzgados
- Guardia Civil
- INEM
- Extensión Agraria
- Universidad
- Centro BUP
- Centro FP
- Academias
- Colegios privados
- Ambulatorio
- Hospital
- Médico general
- Médico especialista
- Farmacia
OTROS
- Discotecas
- Piscinas
- Restaurantes
- Prensa, revistas
¿A QUÉ COMARCA PERTENECE

RO 1
- Electricista
- Reparación coches
- Gasolinera
- Peluquería
- Tintorería
ADMINISTRACIÓN, ENSEÑANZTIEN
- Notarios
- Abogados
- Juzgados
- Guardia Civil
- INEM
- Extensión Agraria
- Universidad
- Centro BUP
- Centro FP
- Academias
- Colegios privados
- Ambulatorio
- Hospital
- Médico general
- Médico especialista
- Farmacia
OTROS
- Discotecas
- Piscinas
- Restaurantes
- Prensa, revistas
¿A QUÉ COMARCA PERTENECE

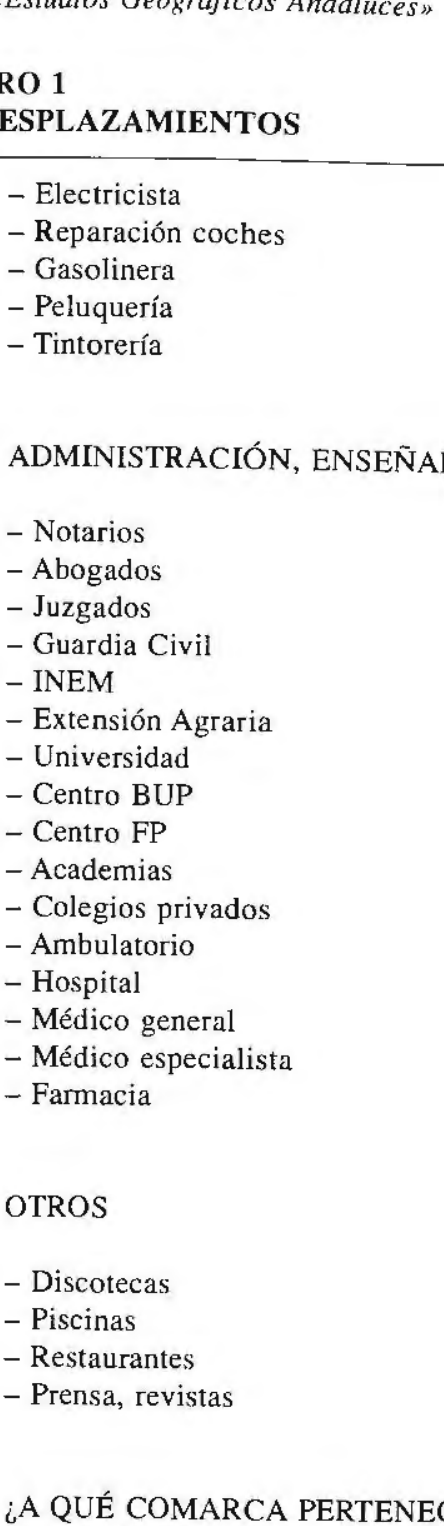

RO 1
- Electricista
- Reparación coches
- Gasolinera
- Peluquería
- Tintorería
ADMINISTRACIÓN, ENSEÑANZTIEN
- Notarios
- Abogados
- Juzgados
- Guardia Civil
- INEM
- Extensión Agraria
- Universidad
- Centro BUP
- Centro FP
- Academias
- Colegios privados
- Ambulatorio
- Hospital
- Médico general
- Médico especialista
- Farmacia
OTROS
- Discotecas
- Piscinas
- Restaurantes
- Prensa, revistas
¿A QUÉ COMARCA PERTENECE

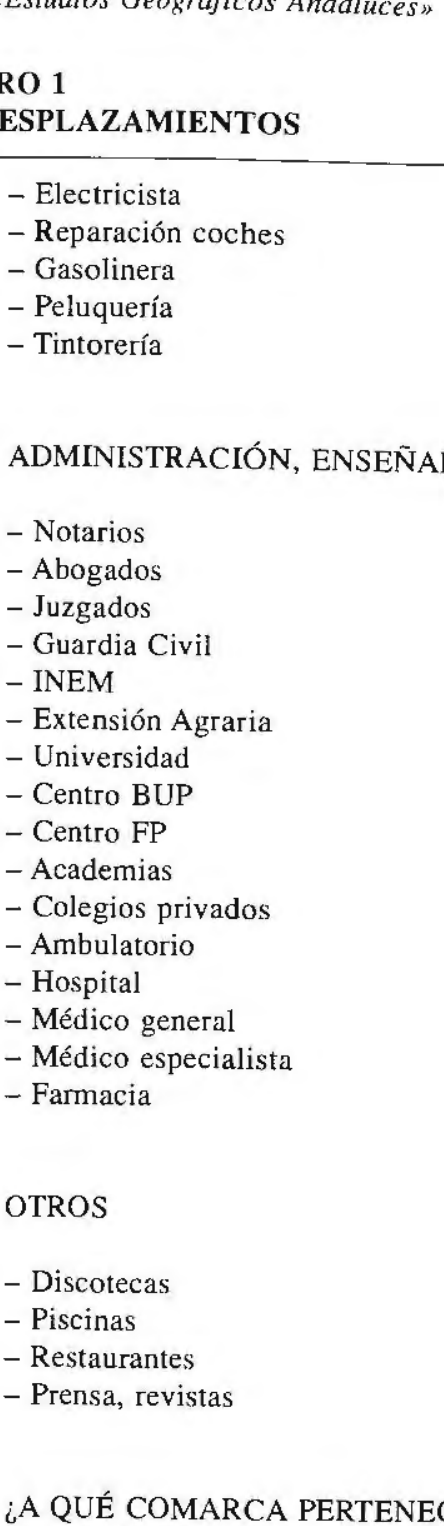

RO 1
- Electricista
- Reparación coches
- Gasolinera
- Peluquería
- Tintorería
ADMINISTRACIÓN, ENSEÑANZTIEN
- Notarios
- Abogados
- Juzgados
- Guardia Civil
- INEM
- Extensión Agraria
- Universidad
- Centro BUP
- Centro FP
- Academias
- Colegios privados
- Ambulatorio
- Hospital
- Médico general
- Médico especialista
- Farmacia
OTROS
- Discotecas
- Piscinas
- Restaurantes
- Prensa, revistas
¿A QUÉ COMARCA PERTENECE

¿A QUÉ COMARCA PERTENECE EL PUEBLO?

¿CUÁL ES LA CAPITAL DE ESA COMARCA?

Fuente: Elaboración propia. 
Considerando la media centena de ofertas/demandas, la casuística es muy alta, desde las urbes total o parcialmente autosuficientes a las pequeñas aldeas dependientes. Por eso cada una de esas 55 referencias en cada uno de los municipios de nuestra Comunidad tiene un tratamiento individualizado y, según el censo municipal y la parte correspondiente asignada (nota 1), se van acumulando en los destinos la población potencialmente atraida (o desplazada, PD desde ahora) por cada centro receptor, lo que mide su carácter de polo, más o menos «necesario», pudiéndose establecer una jerarquización de ciudades.

\section{CUADRO 2}

\section{CLASIFICACIÓN DE LAS 55 OFERTAS/DEMANDAS EN RAZÓN DEL CARÁCTER SELECTIVO DE LA UBICACIÓN}

- Universidad

- Administración Estado

- Administración Autónoma

- Hospital

- Médico especialista

- Informática

- Colegio privado

- Moda

- Confección

- Automóviles

- Fotografía

- Extensión agraria

- Zapatería

- Tintorería

- Juzgados

- Artículos deportivos

- Librería

- Academias

- Optica
- INEM

- Muebles

- Notarios

- Bicicletas y motos

- Abogados

- Relojería y joyería

- Televisión y vídeos

- Comestibles especializados

- Electricista

- Instituto de BUP

- Formación Profesional

- Ambulatorio

- Restaurantes

- Materiales construcción

- Guardia Civil

- Butano

- Autoescuela

- Piscina
- Discoteca

- Ferretería

- Agencia de seguros

- Gasolinera

- Lotería y quinielas

- Reparación de vehículos

- Droguería

- Bancos

- Prensa

- Peluquería

- Carpintería

- Taxis

- Electrodomésticos

- Correos

- Estancos

- Médico general

- Fontanería

- Farmacia

Fuente: Elaboración propia.

Pero después se ponderaron esos movimientos con el peso relativo en Andalucía de cada servicio, obtenidos de las mismas contestaciones, introduciendo así el concepto de población desplazada ponderada (PDP a partir de ahora) como algo más aquilatado que la PD, y que destaca el carácter polarizador. Quizás no haga falta advertir que todo esto no son más que aproximaciones cuantitativas a la realidad y, por ende, discutibles. Pero, en cualquier caso, los datos se utilizan en términos comparativos a fin de discernir la jerarquización urbana y las áreas de influencia, sabiendo que éstas sólo serán parte de una propuesta de comarcalización. 
Pretendemos así colaborar a una mejor organización espacial, administrativa social, económica... de nuestra Comunidad Autónoma y además hay dos asunto. que pueden aportar algún elemento de metodología general; pero cuyo desarrolk podía quedar fuera de contexto en una propuesta de comarcalización y por eso k adelantamos aquí. Nos referimos a la jerarquía urbana y a la caracterización : tipología de los servicios. Lo primero está bastante más estudiado en Geografía pero lo segundo es algo que apenas se ha comenzado y queríamos aprovechar li amplia información conseguida en el macrosondeo mencionado y como un avan ce de publicaciones posteriores.

La introducción de datos fue realizada también por el grupo y el tratamients cartográfico, debatido en conjunto, se debe sobre todo a Angel Luis Lucendo y Je sús Gabriel Moreno. La confección de borradores de mapas y la redacción de est artículo, acabado a principios del 2000, es obra de Gabriel Cano, mientras que la bi bliografía utilizada ha sido recopilada por los miembros del equipo investigador todos ellos coautores de este artículo.

\section{CARACTERIZACIÓN Y TIPOLOGÍA DE SERVICIOS}

\subsection{Geografía y servicios}

El concepto de área de influencia (muy ligado al criterio funcional, desarrolla. do a partir de los años cincuenta, con posterioridad a los espacios naturales, his. tóricos, homogéneos...) y su aplicación a determinados ámbitos cuenta ya con unć amplia bibliografía en los estudios regionales. La mayoría, especialmente en los primeros momentos, se basa en relaciones comerciales y sólo en contadas ocasio nes, y en fechas recientes, se han incluido otros sectores.

Y es que precisamente esa temática está aun poco tratada en Geografía por dos razones principales: la constante aparición de nuevos servicios más la rápida trans. formación de los existentes, de un lado, y las dificultades de contar con fuentes metodologías adecuadas, de otro. Si reparamos en la bibliografía sobre Geografíc de Andalucía, recopilada por F. LOPEZ PEREZ y E. LOPEZ LARA (1990), resultan cosas significativas al respecto.

En Geografía agraria andaluza hay publicaciones específicas por lo menos desd $\epsilon$ principios de los setenta (Bosque Maurel, Manrique, Cano...) y desde mediados de siglo en España, sin contar antecedentes, como los de Burkley, 1906, o Carrión 1932. En cambio, las primeras tesis doctorales sobre comercio y territorio datar de 1985 (ESCOLANO en Aragón) y 1990 (MARQUEZ en Andalucía) y las que versan sobre servicios sanitarios, educativos y de administración andaluces estár 
fechadas ya en los noventa (LOPEZ LARA, VENTURA y NAVARRO LUNA, 1991, 1996 y 1997) y tienen como objetivo básico la búsqueda de áreas de influencia en cada una de esas materias.

Porque existe una ampliación progresiva de servicios y equipamientos que se incorporan a la vida de la población, pero cuyos costes de instalación y mantenimiento exigen una selección de lugar para que sean viables y de fácil accesibilidad. Nos referimos a servicios que generan movilidad, cosa, por cierto, en acelerada transformación, dadas las nuevas vías de comunicación informática y la posibilidad de adquirir bienes, enseñanza, sanidad, etc. a distancia (véase GAMIR, 1997).

\section{CUADRO 3 \\ PORCENTAJES DE DESPLAZAMINENTOS EN ALGUNAS OFERTAS}

Servicio u oferta

$\%$ Municipios con oferta \% Municipios sin ese servicio

Universidad*

Hospital

Informática

Opticas

Juzgados

C. de Enseñanza Media*

Comestibles especializados

Materiales de construcción

Agencias seguros

Discotecas

Banca

Taxis

Fontanería

Farmacias
4.1

4.2

9.3

15.6

18.8

27.8

35.2

46.0

51.0

61.8

65.3

73.9

81.4

93.0
96.9

95.8

91.7

84.4

81.2

72.2

64.8

54.0

49.0

38.2

34.7

26.1

18.6

7.0

* La enseñanza no atañe, ni mucho menos, a toda la población por encima de la edad requerida, si bien en el caso de Ia Universidad podría considerarse atraida en teoría.

Fuente: Elaboración propia con datos del sondeo.

Por otra parte, la disminución de tiempos en los desplazamientos permite una mayor separación de ubicación para cubrir áreas más amplias; de manera que estamos ya muy lejos de la mera consideración comercial de ámbitos y es menester, además, calibrar el peso específico de cada servicio en el espacio. Se pretende, pues, en el presente trabajo un acercamiento a la importancia de los distintos servicios en la organización territorial. 


\subsection{Clasificación}

Cualquier tipología es discutible, pero siempre aporta ideas y dá pasos hací una estructuración consolidada. Nosotros hemos separado las preguntas del cues. tionario en siete grupos: primero, el comercio clasificado en tres apartados (alimentación, vestido y hogar); después, los tres grandes servicios, públicos casi siem. pre, de enseñanza, sanidad y administración; luego un bloque de ocio y cultura al que siguen los servicios y equipamientos relacionados con los transportes. Y finalmente, un grupo heterogéneo de banca, demanda de profesionales liberales reparaciones y servicios personales.

\section{CUADRO 4 \\ CUANTIFICACIÓN DE GRUPOS DE OFERTAS EN PORCENTAJES}

\begin{tabular}{lrrlrl}
\hline & & \multicolumn{4}{c}{ \% de municipios sin esa oferta } \\
\cline { 3 - 6 } Grupos de servicios & \% PD & \multicolumn{2}{c}{ Máximo } & Mínimo \\
\hline COMERCIO & 20.3 & 86.0 & Art. de moda & 14.7 & Estancos \\
ENSEÑANZA* & 15.6 & 95.9 & Universidad & 72.2 & C.E. Media \\
SANIDAD & 11.6 & 96.5 & Hospitales & 7.3 & Farmacias \\
ADMINISTRACIÓN & 20.6 & 92.8 & Ad. Autonómica & 19.2 & Correos \\
OCIO Y CULTURA & 15.4 & 90.7 & Informática & 33.3 & Piscinas \\
TRANSPORTES & 8.4 & 86.4 & V. Automóviles & 26.1 & Taxis \\
OTROS SERVICIOS & 8.1 & 76.1 & Abogados & 18.6 & Fontanería \\
\hline
\end{tabular}

* Media y Superior.

Fuente: Elaboración propia.

Llevados a gráficos los porcentajes de población potencial desplazada y de municipios que carecen de esos servicios, resulta una tipología general que podría ser así:

1. Un grupo de siete ofertas selectivas, localizadas sólo entre el 4 y el $10 \%$ de los municipios y que cada una de ellas tienen una potencia de desplazamiento poblacional superior al $3 \%$ del conjunto de la PDP. Son hospitales, médicos especialistas, universidades, administraciones estatal y autonómica, colegios de enseñanza secundaria y comercios de informática

2. El segundo grupo atañe a doce demandas que se consiguen en el 10-20\% de los municipios con porcentajes de la PDP 2-3 cada una: venta de automóviles, modas, confección y zapaterías especializadas, ópticas, artículos deportivos, tintorerías, librerías, fotografías, además de juzgados, academias e INEM. 
3. Entre el 20 y el $40 \%$ de lo pueblos andaluces poseen catorce servicios, que desplazan el 1-2\% de la población potencialmente atraida. Son ambulatorios, centros de enseñanza media y FP, oficinas de extensión agraria, abogados, notarios y diversas tiendas (motos y bicicletas, muebles, relojerías y joyerías, televisión y vídeos, comestibles especializados, material de construcción), electricistas y restaurautes.

4. Trece ofertas, que por separado atraen sólo al 0.5-1 \% de la PDP, se encuentran en el 45-67\% de los municipios y se refiereu a comercio menos especializado (ferreterías, loterías y quinielas, droguerías, butano), cuestiones relacionadas con vehículos (autoescuelas, reparaciones, gasolineras, agencias de seguros) cultura y ocio (prensa, discotecas, piscinas), Guardia Civil y banca.

5. Del 72 al $93 \%$ de los pueblos de Andalucía disponen de nueve ofertas bastante frecuentes, que sólo ocasionan viajes (desde ese siete-veintiocho por ciento de pequeños municipios que no cuenta con tales servicios) a menos del $0.5 \%$ de la población potencial. Son necesidades de carpintería, fontanería, peluquería, taxis, electrodomésticos, estancos, correos, medicina general y farmacias.

\subsection{Desplazamientos en Andalucía por razones comerciales}

Si añadiésemos al $20.3 \%$ de comercio propiamente dicho, el $16.3 \%$ correspondiente a tiendas incluidas en ocio y cultura y otros servicios (informática, fotografía, artículos deportivos, librerías...), casi alcanzábamos el $37 \%$ de los desplazamientos potenciales; con lo que este apartado, más clásico si se quiere en el tratatamiento, explica muchos de los flujos y de las áreas de influencia. Obviamente en las preguntas no se contemplaba el comercio cuyo umbral demográfico de mantenimiento es mínimo, como por ejemplo las panaderías, por lo que este sector se concentra en los grupos segundo y tercero de la clasificación hecha antes. Mientras que, significativamente, no hay comercios de localización tan selectiva como para integrarse en el grupo de los servicios superiores.

No añade mucho a lo esperado la amplia presencia de tiendas de electricidad, droguerías, ferreterías... y, en cambio, sí se nota la escasez de oferta en ropas de moda, lo que se relaciona con el nivel de vida general, muy por debajo de la media estatal.

\subsection{Oferta de servicios educativos, sanitarios y administrativos}

Desde el enfoque de organización territorial estos servicios ostentan una excepcional relevancia, habida cuentas de que en su gran mayoría son públicos y, por 
lo tanto, suponen aplicar presupuestos en localizaciones adecuadas que potenciat centros comarcales y atraen inversiones privadas. La cadena de equipamientos infraestructuras, redes, desplazamientos, reajustes de población, etc. conllevat precisamente nuevas ordenaciones espaciales.

Las enseñanzas universitarias y medias generan flujos y áreas de influencia po su localización selectiva, sobre todo la primera, y J. VENTURA, que hizo su te sis doctoral sobre esta cuestión (1996), ha redactado lo siguiente para este artí culo:

«Los desplazamientos por razones de estudios universitarios son los más im portantes en la población potencial implicada, mientras los de enseñanza me dia se sitúan en el grupo tercero o intermedio. Tal hecho marca bien las dife rencias de coste y mantenimiento entre ambos niveles de enseñanza y, así mientras en Andalucía hay 30 municipios de los 770 con centros superiores existen 204 con Institutos de BUP o similares y 130 con instalaciones de FI (cuya potenciación parece cada vez más necesaria en orden a una adecuaciót a las demandas sociales). La enseñanza primaria, por su parte, se encuentra er casi todas las localidades».

También los servicios sanitarios andaluces fueron objeto de una Tesis doctora (LOPEZ LARA, 1991) y su autor incluye lo siguiente sobre el tema:

«En la clasificación realizada, los servicios farmaceuticos y de medicina ge neral son prácticamente ubicuos (solo el 7 y $9 \%$ respectivamente no lo tienen) incluso cabe matizar que cuando en algunas respuestas se indican desplazamien tos a Farmacia de otros pueblos se trata a veces sólo para determinados medi camentos. Los ambulatorios, por su lado, se ubican en el grupo intermedio cor 443 municipios equipados y flujos equivalentes a la mitad de la población to tal potencial (PDP)».

De igual forma existe una Tesis doctoral sobre la administración en Andalucí: (NAVARRO, 1997), cuyo autor ha redactado para la ocasión lo que sigue:

«Las administraciones estatal y autonómica generan más desplazamientos : centralidad (en torno a 50 ciudades cuentan con estas prestaciones) y, al igua que otros servicios públicos, marcan cabeceras subregionales y/o comarcales Los Juzgados amplían su presencia (138), reforzando centralidades y subrayand distritos; muchas veces confundidos con comarcas. La importancia espacial d، los tres primeros servicios en razón a desplazamientos queda reflejada en 1: cartografía». 
FIGURA 1

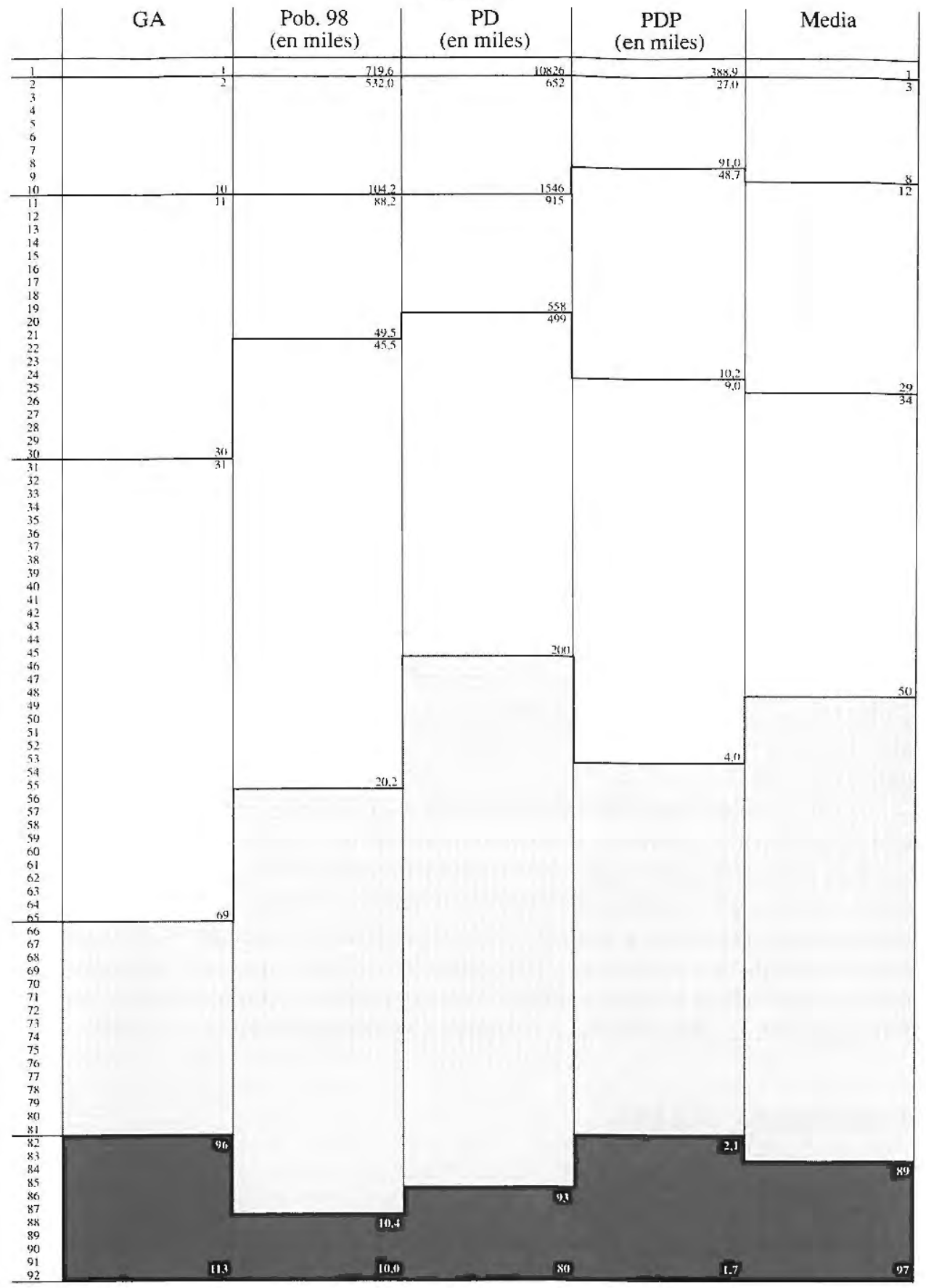


Son, pues, los hospitales y médicos especialistas los que marcan cabeceras comarcales y/o subregionales ( 26 y 42 respectivamente) y se hallan en el grupc de localizaciones selectivas, como la Universidad y la administración estatal y autonómica. Y cabe destacar la importancia de las oficinas de Extensión Agraria en las zonas rurales y las del INEM en un país con tan altas tasas de paro.

\subsection{Otros servicios y equipamientos}

La demanda de ocio y cultura, en aumento al compás del nivel de vida, supone complementos a la enseñanza y se conectan con el turismo, haciendo, pues, de estas ofertas algo muy importante en la búsqueda de centralidades y áreas de influencia.Casi todas ellas pueden incluirse, como dijimos, en el comercio; y tan solo restaurantes, piscinas y discotecas entrarían en otra categoría. En cualquier caso la mayoría se concentran en grupos intermedios, si bien puede hacerse una clara distinción entre, por un lado, los que existen al menos en la mitad de los municipios andaluces (los tres citados más loterías y prensa) y los que están en menos del $30 \%$ de las localidades (venta de material de informática en el diez).

En transportes, con progresiva incidencia de vehículos privados, el taxis consta en las tres cuartas partes de los municipios y la mitad de ellos cuentan con gasolineras, talleres de reparación y agencias de seguros (podrían estar en otro apartado; se colocan aquí para reducir el número de grupos y, en realidad, el seguro obligatorio del coche es el más numeroso). Tan solo el $20 \%$ ofrecen motos y bicicletas y el $14 \%$ venden automóviles; es decir unos 100 núcleos, cifra próxima al número de comarcas que suele manejarse; por ejemplo, las de la Junta de Andalucía de 1983.

La banca se encuentra nada menos que en el $70 \%$ de las localidades, por lo que el desplazamiento generado es pequeño, mientras que las profesiones liberales de notarios y abogados sólo están en la cuarta parte, poco más que las capitales judiciales, con las que se relacionan tales actividades. Finalmente, los servicios del hogar señalan diferentes presencias desde el máximo de fontaneros (600 municipios) al mínimo de electricistas (200), indicando distintos niveles de urgencias. Los servicios personales se hallan mucho más extendidos y, como decíamos para las farmacias, los desplazamientos no siempre suponen ausencia de esa oferta.

\section{JERARQUÍA URBANA}

\subsection{Clasificaciones y límites}

A diferencia de los servicios, el estudio de jerarquías urbanas alcanza una amplia relación de publicaciones, que abarca diferentes épocas (desde, por ejemplo, los 
ya clásicos de BERRY, 1958, o BAILLY, 1978), escaIas (Europa: BRUNET, 1989, PARKINSON, 1991, PRECEDO, 1995; distintos paises y regiones: LOPEZ TRIGAL, 1979, CORTIZO, 1989, SERRANO MARTINEZ, 1983, 1992, 1993), enfoques (además de los numerosos de Geografía, economía regional -RACIONERO, 1978, GALBRAITH, 1967-, planificación urbana: BOVENTER, 1973)...2.

La variable más utilizada ha sido la población totaI municipal, cuyos datos están publicados y suelen ser muy indicativos de la importancia de las ciudades, pero progresivamente se han ido incorporando parámetros y formulaciones matemáticas. Para el caso andaluz elaboramos hace unos años una jerarquía urbana sustentada en 43 elementos (CANO, 1990) y ahora aportamos una clasificación basada en la población que atrae cada núcleo.

En la jerarquización, o relación de polos ordenados, se pueden obtener grupos atendiendo a separaciones o hiatos. En la figura 1 se indican los límites de cinco listas, que son: la señalada de la Geografía de Andalucía (G A., desde ahora), la población de 1998 (P), la población potencialmente atraida (P D), la ponderada según la importancia de los servicios (P D P) y la mediana (M) del orden de cada núcleo en esos cuatro parámetros ${ }^{3}$.

Los grupos de la G A se establecen de acuerdo con los cortes de rango (CANO, 1990); los de la población, aparte de Sevilla/Málaga, cuenta con separaciones muy claras basadas en los $100.000,50.000,20.000$ y 10.000 habitantes, resultando unas divisiones útiles, al menos como puntos de referencia, según veremos. La población potencialmente atraída también ostenta fronteras tan expresivas como las anteriores y no muy distintas. Las divisiones en la PDP tienen en cuenta límites significativos $(50,10,4,2 \ldots)$ relacionados con los niveles anteriores. Y lo mismo para las mayores separaciones de las cifras de las medianas.

El primer lugar de Sevilla es un denominador común en todas estas clasificaciones y, también, que el resto de las capitales de provincia estén en el grupo segundo, pero no exactamente en el mismo orden, como veremos, y además en cuatro de las cinco relaciones entran también Algeciras, Jerez y Ubeda. El bloque tercero supone ya más diferencias; pues, mientras llega en torno al núcleo 20 (PPD, incluso en la M), alcanza el 30 en GA. Una cierta compensación se establece

2. Existen estudios y modelos anteriores, a algunos de las cuales, los más próximos, nos vamos a referir en esta nota. En 1983 J.M. SERRANO publicó un resumen de su Tesis doctoral sobre la red urbana de Murcia, en la que utiliza una serie de servicios y equipamientos para establecer flujos y áreas, tales como la administración, finanzas, enseñanza, sanidad, ocio..., aparte de las comerciales. Nueve años después revisa y actualiza el sistema a la luz de la nueva organización autonómica. En la misma fecha aparece una completa tipología de MORENO y ESCOLANO (1992), atendiendo a distintas variables (foncionales, propiedad, escala de demanda, destinatarios...) y, desde una perspectiva económica, CUADRADO ROURA y DEL RIO presentan en 1983 otra clasificación.

3. Recordemos que se trata de acumular en cada uno la población de los municipios desde donde se acude al núcleo eu euestión para adquirir bienes y servicios. Cuando el origen es compartido por varios destinos, se asigna a éstos un valor aleatorio distribuyendo el $100 \%$ entre las metas. Así se considera la "poblacióu poteneial desplazada» (PD) o atraida por cada ciudad. Pero, como se utilizaban 55 bienes y servicios de distintos pesos relativos, se ponderaron esos potenciales desplazamientos, según la localización selectivas de lasofertas, obteniéndose el concepto de «población potencial desplazada y ponderada» (PDP). 
al final del grupo cuarto, cuyos límites oscilan entre los lugares 45/46 (PD y $55 / 56(\mathrm{P})$.

Sin embargo, atendiendo a cada uno de los núcleos, las diferencias son mayo. res y hemos hallado que las correlaciones significativas se encuentran en la me. diana con la P y la PD. Por eso analizamos ahora las características de la red urbana con los siguientes elementos:

1. Propuesta de la G.A., que encierra más parámetros de ofertas y situaciones económicas que de movilidad.

2. Población de cada municipio, uno de los índices más representativos. Recordemos lo escrito en otros lugares acerca de la diferencia municipioentidad de población, escasa en Andalucía y referidos a núcleos grandes, no afectados por esta cuestión.

3. La movilidad potencial a cada ciudad y pueblo, obtenida del sondeo ya comentado.

4. La variable anterior ponderada según la importancia de los servicios, lo que supone la mayor aproximación de lo elaborado en este estudio.

5. La mediana de los órdenes de las cuatro variables anteriores, que podría ser una propuesta integradora y, por eso, se divide el grupo tercero en dos (con suficientes razones de ruptura de mediana 17.5/22.5), a fin de acercar a las clasificaciones P y PD, por un lado y a la GA y PDP, por otro.

6. Número de pueblos con los que enlazan cada cabecera; importante desde el punto de vista espacial, ya que una ciudad puede tener una PDP elevada, pero nutrida desde otra solamente, $y$, en cambio, se puede ser cabeza de una comarca de pueblos pequeños, que en conjunto no aporte unas cifras grandes de población.

7. Lo anterior obliga a considerar la situación de cada núcleo en el espacio, las características del mismo y las conexiones que se generan.

\subsection{Las capitales de provincia}

Todos esos elementos señalan a Sevilla como cabeza de la red urbana andaluza, excepto en el número de enlaces donde Granada predomina (209 y 185, respectivamente). Sin embargo, es, de entre las ocho, la que cubre su provincia con mayor intensidad de relaciones, especialmente en los servicios administrativos.

De todas maneras el segundo lugar y los siguientes no se hallan tan distantes en muchos de los parámetros lo que hace del andaluz un sistema más equilibrado que otros (Cataluña, por ejemplo). En Andalucía hay dos municipios con más de medio millón de habitantes, ocho pasan de 100.000, once superan los 50.000, dieciseis cuentan más de 30.000 y veintitrés exceden de los 20.000, O lo que es 
igual y acumulando, hay sesenta municipios mayores de 20.000 habitantes, resultado de una rica historia urbana, y repartidos fundamentalmente en el Valle del Guadalquivir, Depresión Intrabética y Costa.

Las otras siete capitales provinciales entran en todas las clasificaciones con los límites señalados; y la comparación de mapas de Cádiz (que marcan las relaciones de los pueblos según se cuenten o no los tres primeros servicios, Universidad, administración estatal y autonómica) dice mucho del peso administrativo de esta urbes (fig. 2). Son las más importantes, además, en el número de habitantes (solo Jerez sobrepasa a algunas: Almería, Cádiz y Huelva) y, por eso, es más significativo analizar el orden de cada una.

Aunque Málaga supera a Granada en tantas cosas (población, economía...), ésta se revela como anterior en el terreno espacial que tratamos por la mayor cantidad de pueblos en el entorno (la provincia de Granada tiene 168 municipios, mientras Málaga 100 y Sevilla 105), sobre todo en un espacio de organización tradicional como la Vega, y con menos centros provinciales próximos de fuerte competencia. Por el contrario, Málaga discute espacio con Antequera, Ronda, Marbella y Vélez Málaga cuando, por otro lado, la mitad aproximadamente de su teórica área de influencia es mar.

La situación de Córdoba coincide aproximadamente en las clasificaciones, destacando en población potencialmente atraida y ponderada (PDP), probablemente por contar en su entorno con municipios muy poblados. Algo similar ocurre con Jaén, aunque lo Ilamativo es la diferencia entre el orden de la mediana o la PDP $\left(5^{\circ}\right)$ y el de la población (9ํ), el mismo que se calculó en la GA. Los órdenes de Cádiz también coinciden y es un caso fácil de explicar: municipio pequeño, prácticamente una isla, con lo que la Bahía es en realidad una conurbación y además cuenta con fuertes competidores como Jerez y Algeciras. Finalmente Huelva y Almería cierran la lista en situaciones espaciales parecidas: preeminencia administrativa reciente (1833) respecto a otras, localización costera con escasa influencia al norte de sus respectivas provincias, poco articuladas y de subdesarrollo tradicional.

\subsection{Centros con más de $\mathbf{5 0 . 0 0 0}$ habitantes}

A las ocho capitales, Andalucía añade trece centros mayores de 50.000 habitantes, pero de muy distinta catalogación en la ordenación espacial. Jerez y Algeciras pertenecen al primer grupo en cuatro de las cinco clasificaciones de la figura primera y a veces en orden anterior a alguna de las ocho, pero hay diferencia entre ambas.La primera atrae con intensidad municipios medianos y pequeños de una parte de la provincia con lo que suma 31 enlace, mientras Algeciras polariza el Campo de Gibraltar con once. Por su parte Linares, Vélez Málaga y 


\section{\% DE POBLACIÓN DESPLAZADA DE CADA MUNICIPIO HACIA LA CAPITAL} $\sum_{S}^{N}$ A. Con todos los servicios.

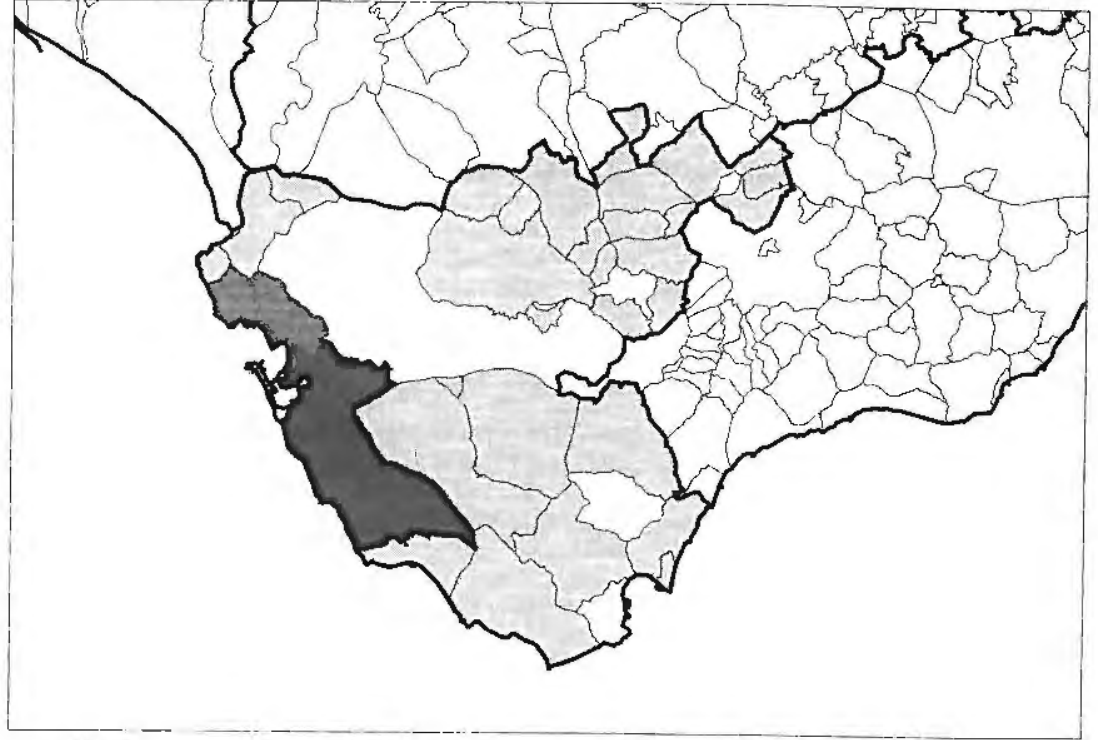

B. Sin los tres primeros servicios.

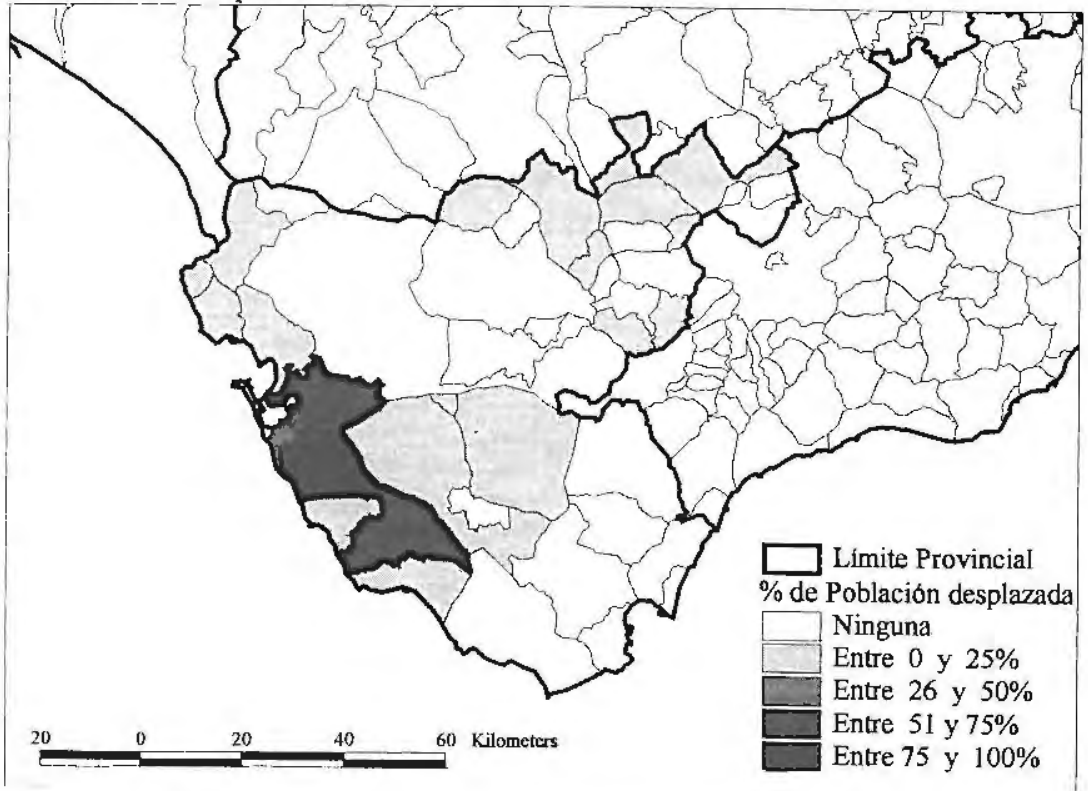


Marbella (en los puestos 12, 16 y 22 de la PDP, mientras se colocan en los 16, 19 y 12 del orden poblacional) centralizan claras áreas de influencia con 34, 26 y 13 enlaces respectivamente, mientras Motril articula la costa granadina.

Por el contrario, las otras siete ciudades andaluzas con más de 50.000 habitantes no son en realidad centros territoriales (en el sentido de organizar espacios y áreas de influencia) y ocupan en esa lista de PDP, que seguimos fundamentalmente, y en el resto de variables lugares lejanos a los correspondientes demográficos. Así Chiclana, El Puerto, Sanlúcar de Barrameda y San Fernando (43, 44, 48 y 80 de la PDP y 20, 14, 17 y 11 de la población), forman una conurbación en la Bahía de Cádiz, atraen a pocos municipios y, en general, con intensidad inferior al $25 \%$. Algo similar ocurre con La Línea (15 P y 37 PDP) respecto a Algeciras; Dos Hermanas (13 y 26) y Alcalá de Guadaira (18 y 44), tan próximas a Sevilla, solo atraen a municipios del sur y sureste provincial con intensidades menores de $25 \%$ que forman parte de las áreas de Utrera y Osuna.

Vemos que una jerarquía urbana ha de analizarse no sólo con variables y formulaciones, sino en su contexto espacial y conociendo la influencia que genera cada núcleo; porque a veces algunos, aunque importantes a otros efectos, no articulan espacios propios. Resulta significativo a este particular que siete de las doce ciudades andaluzas con más de 50.000 habitantes estén en esta situación. Y, al descender en el peso demográfico, vamos a encontrar mas diferencias, si bien continuamos redactando los epígrafes en relación a los habitantes como punto de referencia más conocido.

\subsection{Cabeceras comarcales con más de 20,000 habitantes}

En Andalucía hay treinta y nueve ciudades entre 20.000 y 50.000 , habitantes que restan por considerar. Si comparamos con la relación de PDP incluyendo el grupo cuarto, veinticinco aparecen en la lista y catorce quedan fuera de ella (en donde, a cambio, hay doce con menos de 20.000 h.), pero algunos no son realmente centros territoriales, sino que se integran en el ámbito de otros polos. Así Torremolinos, Benalmádena, Mijas, Fuengirola y Estepona en las áreas de Málaga y Costa del Sol; Roquetas del Mar en la de Almería; Puerto Real, y, en menor medida Rota, en Cádiz; San Roque en Algeciras; Almuñécar en Motril; San Juan de Aznalfarache, Mairena del Aljarafe, Carmona, Camas, La Rinconada y Los Palacios-Villafranca en Sevilla.Y, más discutibles, Lebrija, con escaso espacio entre Utrera y Jerez. Barbate puede encabezar una parte al menos de la Janda.

De las cabeceras de territorios destaca Ubeda, que se sitúa en el lugar 10 de la PDP, mientras está en el 30 de la población con poco más de los 30.000 h. Suma 53 enlaces y articula una parte extensa de la provincia. Andújar cubre el Noroeste y, con escasa intensidad, Alcalá la Real el sur, donde Martos (con 22.000 h., pero 
próximo a Jaén) añade poco. Para encontrar un centro en el nordeste jienense, sil llegar a lo 20.000 h., ni mucho menos, habría que buscar en la lista de la PDP. Villacarrillo (lugar 71), Cazorla (72) o, más centrada en el área, Orcera (lugar 10 de la PDP)

Muy destacados en ese orden, y volviendo a municipios entre veinte y cincuenti mil habitantes, se hallan Antequera (31 enlaces) y Ronda (39), que cubren bueni parte de su provincia y algo de las limítrofes (sobre todo la segunda, que tambiét incluye algunos pueblos de Cádiz). Además de las ya mencionadas en otro nive (Málaga, Vélez y Marbella), Coín aparece con poco espacio entre Ronda y Marbell: pero con cierta influencia en el Valle del Guadalhorce.

Siguiendo con la relación de población potencial atraída y ponderada según li importancia de los servicios (PDP), nos encontramos con importantes centros gra nadinos, como Baza (46 enlaces) y Guadix (43), que cubren el Nordeste y hast: una parte almeriense. Loja (19) y Orgiva (lugar 28 y menos de 20.000 h.) com. pletan el ámbito provincial, además de la misma Granada, claro,

En la circunscripción sevillana sólo nos hemos referido hasta ahora a la capi. tal y centros próximos a ella (San Juan de Aznalfarache, Carmona, Camas, Li Rinconada) más Lebrija, que puede ejercer una cierta atracción. En la PDP cons. tan Utrera, Ecija, Morón y Coria inás Osuna, Estepa, Lora y Sanlúcar la Mayou con menos de 20.000, primeros núcleos sevillanos que aparecen en esta lista, aparte de la capital y su ámbito. Este en realidad abarca prácticamente la provincia, cor lo que es difícil señalar centros reales, si bien existen grandes núcleos con amplios términos, que ya de por sí constituyen «comarcas».

Tal sucede al sur, con Utrera, Morón, Osuna y Estepa de escasa población alrededor, más la competencia de Sevilla e incluso de centros extraprovinciales. Coric del Río llega hasta la marisma y conecta rápidamente con la capital por autovía. Sanlúcar la Mayor atrae parte del Aljarafe, Ecija se sitúa entre Sevilla y Córdoba. mientras Lora del Río alcanza a la Sierra Norte, área próxima a la capital y muy relacionada con ella. Así para encontrar en la lista a Constantina y Cazalla (ya por debajo de los 20.000) hay que llegar al 102 y 115 de la PDP.

Córdoba también polariza bastante su provincia, si bien en el sur se sitúan Lucena, Priego y Cabra, próximos entre sí, (aparte de Puente Genil con más de 20.000 habitantes), mientras que Montilla, cercana a la capital, no sobrepasa en sus 13 enlaces el $25 \%$ de intensidad de atracción; y el norte queda articulado por Pozoblanco y Peñarroya con menos de 20.000 h. La provincia de Cádiz, con la Bahía, Jerez y Algeciras queda prácticamente cubierta y para encontrar algún otro centro hay que alcanzar el lugar 66 de la PDP, donde hallamos Arcos, demasiado próximo a Jerez, aunque con cierta área funcional.

En los extremos de la Comunidad, Almería y Huelva no llegan, como vimos, a la parte septentrional de sus respectivas provincias. En el primer caso El Ejido y Adra son poblaciones meridionales con más de 20.000 habitantes, pero sólo la 
primera aparece en la lista de la PDP antes del número 53. Sí están las septentrionales de Huércal Overa y Vera con menos de 20.000 , mientras la parte más extrema (Vélez Rubio 6.500 h. y lugar 84) conecta menos con el sistema capitalino. El Valle del Almanzora, por su parte, es asiento de varios núcleos de cierta importancia, sobre todo económica en torno al mármol, pero como centro territorial Albox, 10.000 h., aparece en el lugar 63 de la PDP.

En Huelva no hay ningún polo funcional, excepto la capital, que pase de los $20.000 \mathrm{~h}$. (aunque existen núcleos emergentes, como Lepe, próximo a esa cifra), pero el norte está mejor articulado que el almeriense, especialmente la parte oriental con Aracena; mientras en el centro se halla Valverde y Minas de Riotinto, sede del Hospital comarcal y atracción extensa pero débil. La Palma del Condado añade poco al sistema y la parte occidental, fronteriza con el Algarve y el Alentejo meridiona, está muy desarticulada: Cortegana, Puebla de Guzmán y Ayamonte, de norte a sur, dibujan áreas de poca intensidad.

\subsection{Una posible clasificación del sistema urbano andaluz}

Según las anteriores agrupaciones y comentarios, más las situaciones espaciales de cada núcleo, podemos establecer la siguiente clasificación (fig. $n^{0} 3$ ):

\section{A) CAPITALES DE PROVINCIA}

Son las ciudades más pobladas (además de Jerez que supera a cuatro de ellas) $y$, sobre todo, concentran una serie de ofertas y servicios, especialmente administrativos, que atraen a poblaciones del entorno, en algún caso prácticamente la provincia. Pero caben distinciones entre ellas.

SEVILLA. Con más de 700.000 habitantes, un área metropolitana en crecimiento, cabecera de una amplia y poblada provincia más la capitalidad autonómica hacen de ella el primer centro de atracción andaluz

CORDOBA. Aunque es la tercera en población y, como vimos, según qué variable se utilice, su lugar oscila entre el 2 y el 5 , tiene uno de los términos municipales más grandes de Andalucía y ejerce su influencia directa hasta los Pedroches y en toda la Campiña hasta el Subbético

MALAGA, GRANADA Y JAEN. Se diferencian de otras y se asemejan entre sí por la existencia de importantes centros que articulan claramente gran parte de sus respectivas provincias. Son los casos de Vélez Málaga, Antequera, Ronda y Marbella; Guadix, Baza y Motril; Andújar, Linares y Ubeda.

ALMERIA Y HUELVA. Por el contrario, ni compiten en el espacio con grandes núcleos, como las anteriores, ni tampoco ejercen la influencia que Sevilla o 


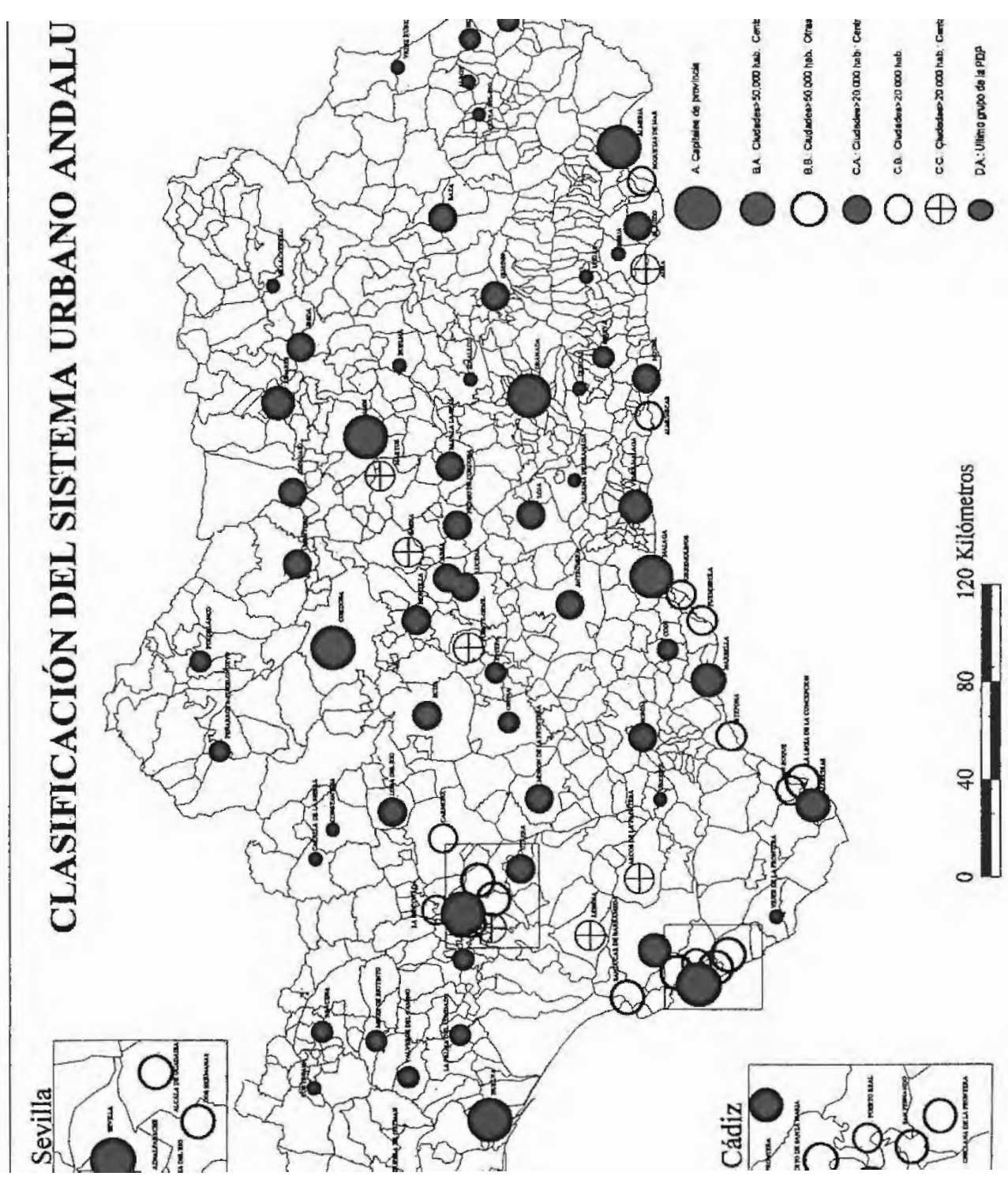


Córdoba tienen en sus provincias. Se trata de las dos capitales de distritos administrativos más recientes en sendos territorios periféricos, desarticulados y de subdesarrollo secular.Hoy cuentan con un importante turismo y rica agricultura, si bien sus respectivas influencias no alcanzau la parte septentrional.

CADIZ. Su carácter de isla, la pequeñez del término y la proximidad de varias ciudades (Jerez, San Fernando, El Puerto...) reducen considerablemnte su área de influencia en una provincia donde las Campiñas de Jerez y el Campo de Gibraltar poseen una entidad territorial indudable.

B) CIUDADES MAYORES DE 50.000 HABITANTES

\section{B.A) CENTROS TERRITORIALES}

Además de Jerez y Algeciras, están Marbella, Linares y Vélez Málaga. Las dos litorales articulan sendos espacios al oeste y este de la capital. Marbella, aparte sus ya casi 100.000 h. y su importancia económica, turística, etc., centra la Costa del Sol, mientras Vélez Málaga con similares características de economías recientes es la capital de una antigua comarca, la Axarquía. Linares, importante centro industrial, organiza por su lado una parte de Jaén.

\section{B.B) OTRAS CIUDADES}

Los siete municipios restantes con más de 50.000 h. no organizan realmente territorios en el sentido que venimos analizando (el de mayor atracción ocupa el lugar 26 de la PDP), sino ciudades en el entorno de otras más importantes sin espacio propio (Dos Hermanas y Alcalá de Guadaira -lugar 94-, respecto a Sevilla y La Línea con Algeciras) o forman conurbación con otras, como San Fernando (80), Puerto de Santa María y Chiclana, y, lo que puede ser más discutible, Sanlúcar de Barrameda (48) en la Costa noroccidental gaditana.

C) MUNICIPIOS CON MAS DE $20.000 \mathrm{H}$.

\section{C.A) CENTROS TERRITORIALES}

Además de los veinte ya comentados y Lora del Río con más de 19.500, hay 36 municipios mayores de $20.000 \mathrm{~h}$., de los que 18 articulan áreas de influencia, según los datos de flujos disponibles. En primer lugar Ubeda, una de las ciudades andaluzas con mayor e intensa atracción, que alcanza hasta el Nordeste provincial 
de las Sierras de Segura, Cazorla etc. También Andújar, menos important espacialmente, entra en esta categoría, así como Alcalá la Real en el sur jiennense

Antequera y Ronda, en torno a los 40.000 h., son centros históricos con área: de atracción consolidadas, que en el caso segundo llega hasta la Sierra de Cádiz En Granada, Motril (prácticamente con 50.000), Baza y Guadix, componen, as mismo, claros ámbitos; mientras Loja, de parecido peso demográfico (poco más de los veinte mil ciudadanos), atrae bastante menos, al quedar en el extremo pro. vincial, constreñida entre la Vega y Antequera con la competencia también de Alhama en un espacio de escasa división municipal.

En Sevilla, Utrera, Ecija, Morón y Lora componen ámbitos (ésta última de forma débil), al igual que Lucena, Priego y Cabra (Montilla se incluye aquí perc es más discutible). Cádiz no dispone de centros de este tipo, ni tampoco Huelva: Almería sólo El Ejido, cercano a la capital y de espectacular crecimiento demográfico reciente.

\section{C.B) OTROS MUNICIPIOS CON MAS DE $20.000 \mathrm{H}$}

Hay once núcleos de este tamaño que en realidad no son cabeceras comarcales y ocupan en la relación de la PDP lugares posteriores al 35 (San Juan de Aznalfarache), a excepción de Puerto Real (24). Como en estos dos casos son ciudades próximas a otras de más importancia espacial: San Roque (93), Torremolinos, Fuengirola (135) Estepona, Almuñécar, Roquetas, Camas, Carmona y La Rinconada (89) en la PDP).

\section{C.C) CENTROS DUDOSOS}

Los restantes mayores de 20.000 habitantes generan poca atracción (lugares de la PDP entre 60 y 110) y se ubican cerca de otras cabeceras, pero son casos dudosos, que consideraremos más a fondo en su momento, y podrían entrar en el grupo C). Se trata de Arcos, cerca de Jerez; Lebrija, que, asímismo, se sitúa con cierta influencia entre las provincias de Sevilla y Cádiz; Coria, que ejerce alguna atracción hacia el sur marismeño, Puente Genil y Baena en Córdoba, además de Martos y Adra poco distantes de sus respectivas capitales.

\section{D) POSIBLES CABECERAS TERRITORIALES CON MENOS DE $20.000 \mathrm{H}$.}

A la hora del análisis espacial los centros territoriales citados (A, B.A. y C, más los últimos cinco dudosos) dejan espacios sin articular, lo que obligaría a buscar 
en las listas manejadas núcleos que pudieran ejercer como centros territoriales. Habria dos grupos: el que se incluye hasta el lugar 53 de la PDP y los que se hallan en lugares más lejanos.

\section{D.A) INCLUIDOS HASTA EL CUARTO GRUPO DE LA PDP}

Son trece y se sitúan entre el lugar 19 de la PDP y el 53, último de los considerados aquí, con poblaciones superiores a los 10.000 (incluyendo La Palma del Condado próxima a esa cifra), excepto Vera, Orgiva, Aracena y Minas de Riotinto que no alcanzan esa cantidad, pero sí pasan de los 5.000 .

Su función territorial es la siguiente: en Almería Huércal Overa y Vera son los referentes del nordeste provincial. Orgiva es el principal centro de la Alpujarra granadina y Coín (cercano a los 20.000 h. y en el puesto 39 de la PDP) organiza un área de influencia entre Málaga, Marbella y Ronda. Los Pedroches se dividen en dos centros claros en torno a los 15.000 h., Pozoblanco y Peñarroya, mientras en Sevilla, Sanlúcar la Mayor se constituye en capital del Aljarafe, a la vez que Estepa y Osuna centran espacios de fragmentación adecuada en la provincia más o menos equiparables a Ecija, Morón y Utrera. Finalmente Huelva, donde, salvo la capital, no hay centros con más de 20.000 h., como dijimos, necesita, al menos, potenciar como polos territoriales a Valverde del Camino en el Andévalo y Minas de Riotinto (sobre todo por la existencia del hospital comarcal), Aracena en el norte y, quizás, La Palma del Condado (próxima a los 10.000 h. y la última de la lista de los 53 lugares de la PDP).

\section{D.B) OTROS CENTROS}

En esa situación hay algunos núcleos en los que convendría aumentar las ofertas a fin de que ejercieran mayores funciones espaciales. Serían como 17, de los que cinco cuentan con más de 10.000 habitantes, diez pasan de 5.000 y dos están en los 3.000. En Huelva, aparte de los incluidos antes, queda desarticulado el oeste lindante con el Algarve, por lo que Ayamonte ( 16.000 h. y lugar 75 de la PDP) está llamado a un mayor protagonismo y también algún pequeño núcleo en el Andévalo occidental: Puebla de Guzmán, de sólo 3.000 h., y de una extensa aunque débil atracción, o Villanueva de Cástillejo-El Almendro. Quizás Cortegana (5.000 h.) complete la Sierra Norte con Aracena.

A pesar de la gran cantida de centros mencionados en Sevilla, la Sierra Norte precisa un mayor desarrollo de Cazalla y Constantina y también la urbanizada provincia gaditana requiere un polo, que debe ser Ubrique, pueblo industrial de casi 20.000 h., aunque en el lugar 98 de la PDP. Y, quizás, otro para encabezar un espacio (¿la Janda?) entre la Bahía de Cádiz, Campo de Gibraltar y Jerez. 
Málaga y Córdoba tendría cubiertas sus necesidades territoriales, al menos : la escala en que nos movemos, mientras Jaén precisa un centro en las sierra: norocidentales, que podría ser Villacarrillo (más de 12.000 h. y próximo al fina de la lista, 56, de la PDP) y otro al sur, quizás Huelma (6.000 h.), en una comar ca tradicional, los Montes, entre las provincias de Granada y Jaén, donde, ademá: de la ya mencionada Alcalá la Real, contaría también Iznalloz (7.000) en el ladc granadino.

Aquí, por otra parte, es menester considerar a Huéscar (10.000) en el norte, que casi está polarizado por Baza, sobre todo con las mejoras de las comunicaciones Al suroeste quizás haya que reparar en Alhama $(6.000$ h.) y el Valle de Lecrín cor Dúrcal (6.000 h. y lugar 74 de la PDP). En las Alpujarras, que carece de un centro importante, habría que sumar a Orgiva, Ugíjar (3.000) y Bérja (13.000) ya en Almería, donde se necesita añadir centros en el Almanzora, como Albox (10.00C habitantes) y Olula, 6.000. Al norte la histórica comarca de los Vélez tiene como posible centro a Vélez Rubio.

\section{E) OTROS MUNICIPIOS MAYORES DE $10.000 \mathrm{H}$.}

Quedan aún 25 localidades con un censo superior a los que algunos consideran municipio urbano. Unos demasiado cerca a grandes ciudades y, por lo tanto, su función espacial no es más que la de un barrio de aquéllas Son los casos de Armilla en Granada y Castilleja de la Cuesta en Sevilla. Otros, no tan próximos, carecen de espacio y ofertas de servicios para organizar ámbitos.

\section{4. ÁREAS FUNCIONALES Y COMARCAS ANDALUZAS}

Con esa clasificación, considerando ciudades y pueblos que organizan áreas de influencia, se puede dibujar una división territorial de tipo funcional, cuya precisión de límites no exponemos ahora. En Almería, Vélez Rubio encabeza el norte; el Valle del Almanzora es polinuclear (Albox y Ulula), así como el Levante con Vera y Huércal Overa. En el sur, además del distrito capitalino, el Ejido nuclea el Poniente y en el centro, las Alpujarras y el Campo de Tabernas no cuentan en realidad con centros.

En Granada se localizan Baza, Guadix, Iznalloz (los Montes), Loja, Alhama, Dúrcal (Valle de Lecrín), Orgiva (Alpujarra) y Motril. El norte, zona de Huéscar, queda desarticulado y un tanto lejos de Baza, por lo que cabría aplicar otros criterios no funcionales. Málaga queda perfectamente cubierta con Antequera, Ronda, Marbella, Coín y Vélez Málaga. Lo mismo que Cádiz con Jerez, Algeciras,Sanlúcar, Vejer o Barbate en la Janda, y la Sierra, con Arcos y Ubrique. 
Aracena organiza el norte de Huelva, mientras el sur, aparte la capital, cuenta con Ayamonte y la comarca de Doñana. En el centro, Palma del Condado, la Cuenca Minera, Valverde y, para articular el oeste del Andévalo, Puebla de Guzmán. En la provincia de Sevilla, la Sierra Norte (Constantina y Cazalla), la Vega (Lora), Ecija, Carmona, Sierra Sur, Morón, Lebrija, Sanlúcar la Mayor y Coria (AljarafeMarisma).

Córdoba distribuye su territorio entre Pozoblanco y Peñarroya al norte; al sur, un Subbético polinuclear (Priego, Lucena, Puente Genil) y las Campiñas (Baena y Montilla); y en el valle, la capital, Montoro y Palma del Río. En Jaén Andujar, Linares, Ubeda, Huelma, Alcalá la Real y Martos, pero con otros criterios no funcionales habría que articular los espacios del Condado, sierras de Segura y Cazorla.

\section{CONCLUSIONES: CIUDADES, SERVICIOS Y ESPACIOS}

A la vista de todo lo anterior podemos caracterizar brevemente los espacios andaluces en relación a los centros y sus áreas de influenciá. Existe una buena distribución en el Valle del Guadalquivir, Depresión Intrabética y Costa, lo que concuerda con los conocidos rasgos del solar andaluz. Pero también en el Subbético y en la Penibética, quedando poco articulada gran parte de Sierra Morena más el norte de Huelva y Almería. Es decir, que, a la vista del mapa adjunto, es la zona periférica andaluza (exactamente la terrestre, que linda con Portugal, Extremadura, La Mancha y Murcia) la que carece de centros articuladores.

Así el Valle cuenta con importantes núcleos que organizan espacios o comarcas y que de este a oeste son: Ubeda, Jaén, Linares (ciertamente las capitales no se localizan en el Valle, pero sí buena parte de sus áreas), Andújar, Córdoba, Montilla, Ecija, Lora del Río, Sevilla, Coria, Utrera, Lebrija y Jerez.

En la Depresión Intrabética se suceden Baza, Guadix, Granada, Loja y Antequera. Y en la Costa están los ámbitos de Almería, El Ejido, Motril, Velez Málaga, Málaga, Marbella, Campo de Gibraltar, Bahía de Cádiz y Huelva. Las Sierras Penibéticas cuentan con el importante centro de Ronda, pero también con comarcas históricas de pequeños municipios, escasamente polarizada, como las Alpujarras, o polarizada por Vélez Málaga, caso de la Axarquía. En el Subbético, además de Jaén, la comarca de losMontes, a caballo entre dos provincias, y, en su periferia, Alcalá la Real. En la parte cordobesa, Cabra, Lucena y Priego; en Sevilla, Estepa, Osuna y Morón.

Por el contrario, Sierra Morena, si quitamos Linares, solo cuenta con núcleos de poco peso y dificultades de articulación por las deficiencias en comunicaciones y una economía de islotes industriales, mineros y turísticos, que quizás la existencia de Parques Naturales debería potenciar más. El Andévalo y la frontera 
con el Algarve están poco organizados, así como el espacio lindante con Murci. y el mismo Valle del Almanzora, que, no obstante, cuenta con buenas condicione económicas, aunque con un excesivo fraccionamiento municipal.

\section{BIBLIOGRAFÍA CITADA}

BAILLY, A.S.: La organización urbana.Teorías y modelos, Madrid, 1978, 278 pp.

BRUNET, R.: Les villes européenes, París, Informe para la DATA, 1989.

CANO GARCIA, G.: "Territorios andaluces. Aproximación a una comarcalización», Geografí de Andalucía, Tomo VIII, Sevilla, Ed. Tartessos, 1990, pp. 205-259.

CANO GARCIA, G.: «Comarcas y articulación del Territorio.Algunos ejemplos andaluces»: Revista de Estudios Andaluces, n² 21, 1995.

CORTIZO ALVAREZ, J.: Los asentamientos en la provincia de León: comercio, servicios jcrarquía funcional. León. Secretariado de Publicaciones de la Universidad, 1989, 272 pF CUADRADO ROURA y DEL RIO GOMEZ: Los servicios en España, Madrid, Ed. Pirámide 1993, $190 \mathrm{pp}$.

ESCOLANO, C.: Comercio y territorio en España, Zaragoza, Publicaciones de la Universidad 1988.

GALBRAITH: El nuevo estado idustrial, Barcelona, Ariel, 1967.

GAMIR ORUETA, A.: «Los procesos de cambio en los servicios personales y el comercio: auto servicio, telecompra y teleserviciom, Boletín de la A.G.E., n"24, 1997, pp. 13-27.

GRUPO DE ESTUDIOS GEOGRAFICOS ANDALUCES (Director G. Cano): «Aportaciones la Comarcalización de Andalucía», I Congreso de la Asociación Andaluza de Ciencia Re gional, Jerez, 1997.

LOPEZ LARA, E.: Salud y territorio. Geografía médica y asistencial en Andalucía, tesis docto ral, Sevilla, 1991.

LOPEZ PEREZ y LOPEZ LARA: «Bibliografía», Geografía de Andalucía, (Cano, Director) Sevilla, Ed. Tartessos, Tomo VIII, 1987-90, pp. 261-298.

LOPEZ TRIGAL, L.: La red urbana de León. Análisis de Geografía regional, León, 1979 MARQUEZ DOMINGUEZ, J.: Comercio y territorio en Andalucía, Cámara de Comercio Industria y Navegación de Andalucía, 1990, 509 pp.

MORENO JIMENEZ y ESCOLANO UTRILLA: Los servicios y el territorio, Madrid, Ed Síntesis, 1992, $189 \mathrm{pp}$.

NAVARRO LUNA, J.: Administración y servicios públicos en Andalucía.Análisis territorial diferentes escalas, Tesis doctoral, Sevilla, 1997.

PARKINSON, M.: Urbanization and the funtion of cities in the European Community, 1991 PRECEDO LEDO, A.: La red urbana de la Unión Europea y la Organización del Territorio, 1995 RACIONERO, L.: Sistema de ciudades y ordenación del territorio, Madrid, 1978.

SERRANo MARTINEZ, J.M.: La red urbana de Murcia, Secretariado de Publicaciones, 1983 67 pp. y anexos.

SERRANO MARTINEZ, J.M.: Modificaciones del sistema urbano regional de Murci (1980-1990) dentro de la nueva organización autonómica, Murcia, AMCR, 1992, 131 pF

SERRANO MARTINEZ, J.M.: Area metropolitana de Murcia. Análisis de un centro urbano el su borde sur, Murcia, Publicaciones de la Universidad, 1993.

VENTURA FERNANDEZ, J.: Los servicios educativos en Andalucía.Territorio y planificacióı sectorial, Tesis doctoral, 1996. 